Diversidade de Flebotomíneos (Diptera, Psychodidae, Phlebotominae) e detecção molecular de parasitas do gênero Leishmania no município de Bom Jesus dos Perdões, estado de São Paulo

São Paulo

2016 


\section{Diversidade de Flebotomíneos (Diptera, Psychodidae, Phlebotominae) e detecção molecular de parasitas do gênero Leishmania no município de Bom Jesus dos Perdões, estado de São Paulo}

Dissertação apresentada ao Programa de PósGraduação em Epidemiologia Experimental Aplicada ás Zoonoses da Faculdade de Medicina Veterinária e Zootecnia da Universidade de São Paulo para a obtenção do título de Mestre em Ciências

\section{Departamento:}

Medicina Veterinária Preventiva e Saúde Animal

Área de concentração:

Epidemiologia Experimental Aplicada ás Zoonoses

Orientador:

Prof. Dr. Arlei Marcili

De acordo:

Orientador(a)

São Paulo

2016 
Autorizo a reprodução parcial ou total desta obra, para fins acadêmicos, desde que citada a fonte.

\section{DADOS INTERNACIONAIS DE CATALOGAÇÃO NA PUBLICAÇÃO}

(Biblioteca Virginie Buff D’Ápice da Faculdade de Medicina Veterinária e Zootecnia da Universidade de São Paulo)

Costa, Luís Eduardo da Silva

Diversidade de Flebotomíneos (Diptera, Psychodidae, Phlebotominae) e detecção molecular de parasitas do gênero Leishmania no município de Bom Jesus dos Perdões, estado de São Paulo / Luís Eduardo da Silva Costa. -- 2016.

$$
59 \text { f. : il. }
$$

Dissertação (Mestrado) - Universidade de São Paulo. Faculdade de Medicina Veterinária e Zootecnia. Departamento de Medicina Veterinária Preventiva e Saúde Animal, São Paulo, 2016.

Programa de Pós-Graduação: Epidemiologia Experimental Aplicada às Zoonoses.

Área de concentração: Epidemiologia Experimental Aplicada às Zoonoses.

Orientador: Prof. Dr. Arlei Marcili.

1. Flebotomíneos. 2. Leishmania. 3. Leishmaniose tegumentar. 4. Leishmaniose visceral. 5. Bom Jesus dos Perdões. I. Título. 
UNIVERSIDADE DE SÃO PAULO

Comissão de Ética no Uso de Animais

São Paulo, 21 de março de 2014

\title{
CERTIFICADO
}

Certificamos que o Projeto intitulado "Diversidade de Flebotomíneos (Diptera, Psychodidae, Phlebotominae) e deteç̧ão molecular de parasitas do gênero Leishmania no Município de Bom Jesus dos Perdões, estado de São Paulo.", protocolado sob o CEUA nº 6774240114 , sob a responsabilidade de Arlei Marcili, foi aprovado na reunião de 12/03/2014, e está de acordo com os princípios éticos da Comissão de Ética no Uso de Animais da Faculdade de Medicina Veterinária e Zootecnia da Universidade de São Paulo.

We certify that the Research "Diversity of Phlebotomines (Diptera, Psychodidae, Phlebotominae) and molecular detection of Leishmania species in the municipality of Bom Jesus of Perdões, State of São Paulo.", protocol number CEUA 6774240114, under the responsibility Arlei Marcili, was approved in the meeting of day 03/12/2014, and agree with Ethical Principles adopted by Ethic Committee on Animal Use of the School of Veterinary Medicine and Animal Science of the University of Säo Paulo.

\author{
Atenciosamente, \\ Joriug tanbin \\ Profa. Dra. Denise Tabacchi Fantoni \\ Presidente da Comissão de Ética no Uso de Animais \\ Faculdade de Medicina Veterinária e Zootecnia \\ Universidade de São Paulo
}


Autor: COSTA, Luís Eduardo da Silva

Título: Diversidade de Flebotomíneos (Diptera, Psychodidae, Phlebotominae) e detecção molecular de parasitas do gênero Leishmania no município de Bom Jesus dos Perdões, estado de São Paulo.

Dissertação apresentada ao Programa de Pós-Graduação em Epidemiologia Experimental Aplicada ás Zoonoses da Faculdade de Medicina Veterinária e Zootecnia da Universidade de São Paulo para obtenção do titulo de Mestre em Ciências

Data:

1

\section{Banca Examinadora}

Prof. Dr.

Instituição: Julgamento:

Prof. Dr. Instituição: Julgamento:

Prof. Dr. Instituição: Julgamento: 


\section{DEDICATÓRIA}

Dedico este trabalho aos amores da minha vida, Ângela, Pedro e Ana Julia, pelo apoio, compreensão e paciência pela minha ausência em muitos momentos, durante as noites de coleta, idas a São Paulo e reclusão estudando e concluindo esta pesquisa. 


\section{AGRADECIMENTOS}

Agradeço a Deus pelo dom da vida, pelas pessoas que fizeram e fazem parte dela e pela fé que nunca me deixa desistir e desanimar nos momentos de dificuldades.

Ao Professor Dr. Arlei Marcili, pela oportunidade, confiança, amizade e por todo o incentivo e orientação, imprescindíveis para a conclusão deste trabalho e para meu crescimento acadêmico e profissional, sempre terá meu respeito e admiração.

À Professora Dra. Eunice A. B. Galati, pelos ensinamentos, apoio e a generosidade em permitir que iniciasse todo o trabalho de identificação dos flebotomíneos com a sua equipe no Laboratório de Entomologia em Saúde Pública/Phlebotominae da Faculdade de Saúde Pública da Universidade de São Paulo - USP.

À Mestre Priscila B. Sábio, pela amizade, orientação e ajuda no processo de clarificação, montagem e identificação dos flebotomíneos e por toda a preciosa colaboração.

Aos colegas do Laboratório de Entomologia em Saúde Pública/Phlebotominae da Faculdade de Saúde Pública da Universidade de São Paulo - USP, Dr. Fredy Galvis Ovallos, Dra. Marcia Bicudo de Paula e Cecília de Oliveira Lavitschka, pelo apoio, orientação e paciência no tempo em que estivemos juntos.

A Professora Dra. Márcia Aparecida Sperança e sua equipe do laboratório de Genética Molecular - Campus São Bernardo do Campo, Centro de Ciências Naturais e Humanas - UFABC, por toda a ajuda.

Aos colegas da equipe TRIP/LEISH, do Laboratório de Doenças Parasitárias do VPS da FMVZ da Universidade de São Paulo - USP, Andréa, Juliana, Bruna e Ryan, pelo apoio e incentivo, onde estavam sempre prontos em ajudar e por todos os momentos que passamos juntos.

A todos os Professores, funcionários e colegas do Departamento de Medicina Veterinária Preventiva e Saúde Animal - VPS, da Faculdade de Medicina Veterinária e Zootecnia da Universidade de São Paulo - USP, pelos ensinamentos e o privilégio do convívio durante o tempo em que estivemos juntos. 
À Faculdade de Saúde Pública da Universidade de São Paulo - USP e seus Professores pelos ensinamentos.

A Fundação de Amparo à Pesquisa do Estado de São Paulo (FAPESP), por apoiar esse trabalho.

Ao Sistema de Autorização e Informação em Biodiversidade (SISBIO) pelas autorizações concedidas.

A todos os queridos companheiros da Secretaria de Saúde de Bom Jesus dos Perdões, que me apoiaram e acompanham desde o início deste trabalho, em especial a Secretária de Saúde Sra. Ana Lucia de Almeida e todos os amigos do setor de Vigilância em Saúde, principalmente os que me ajudaram no trabalho de campo, com as capturas dos flebotomíneos: Amauri Rodrigues e Daniel Leme Pedroso e na coleta de dados no SINAN: Camila Grasseti de Moraes.

Ao amigo Erick Zambelli Rey, pela colaboração nas coletas.

Ao meu querido irmão, Mestre Luís Flávio da Silva Costa, pelo incentivo em iniciar esse trabalho de Mestrado e por todo nosso companheirismo no trabalho e na vida.

A minha querida Mãe, Mirian e meu Pai e melhor amigo, Luiz Antônio (in memoriam) por terem me dado o amor e bons exemplos para trilhar o caminho do bem. 
"O Amor é paciente, é benigno; não é invejoso, não trata com leviandade, não se ensoberbece, não se porta com indecência, não busca os seus interesses, não se irrita, não suspeita mal, não folga com a injustiça, mas folga com a verdade. Tudo tolera, tudo crê, tudo espera, tudo suporta. O Amor nunca falha."

Paulo de Tarso 


\section{RESUMO}

COSTA, L. E. S. Diversidade de Flebotomíneos (Diptera, Psychodidae, Phlebotominae) e detecção molecular de parasitas do gênero Leishmania no município de Bom Jesus dos Perdões, estado de São Paulo. [Diversity of Phlebotomines (Diptera, Psychodidae, Phlebotominae) and molecular detection of Leishmania species in the municipality of Bom Jesus of Perdões, state of São Paulo]. 2016. 59 f. Dissertação (Mestrado em Ciências) - Faculdade de Medicina Veterinária e Zootecnia, Universidade de São Paulo, São Paulo, 2016.

Os flebotomíneos são dípteros hematófagos pertencentes à família Psychodidae e subfamília Phlebotominae. Considerando o processo migratório da doença no Estado de São Paulo e a complexidade da relação parasito/vetor/hospedeiros da Leishmaniose é necessário realizar estudo sobre os aspectos ecológicos e epidemiológicos desta doença. A expansão da Leishmaniose no interior paulista está associada aos processos antrópicos e ao desequilíbrio ambiental. O município de Bom Jesus dos Perdões passa por um crescente processo de urbanização onde não é conhecida a fauna de flebotomíneos, bem como a pesquisa de parasitas do gênero Leishmania nestes vetores. O presente projeto teve por objetivo principal, a Identificação da fauna de flebotomíneos (Diptera, Psychodidae, Phlebotominae) e detecção molecular de parasitas do gênero Leishmania no Município de Bom Jesus dos perdões, Estado de São Paulo. Os flebotomíneos foram coletados com armadilha do tipo CDC e armadilha de Shannon, em 12 pontos em três diferentes ambientes, sendo áreas de mata, área Periurbana e áreas urbanas. A taxonomia alfa foi baseada na chave dicotômica descrita por Galati (2003) e o nome das espécies foram abreviado segundo Marcondes (2007). Para a pesquisa de parasitas do gênero Leishmania foram utilizados marcadores baseados nos genes SSU rDNA, citocromo e quitinase. No município de Bom Jesus dos Perdões foi registrada uma riqueza de 12 espécies de flebotomíneos distribuídos em duas Subtribos: Subtribo Lutzomyiina com Migonemyia migonei, Pintomyia fischeri, Pintomyia monticola, Pintomyia misionensis, Evandromyia edwardsi e a Subtribo Psychodopygina com Psathyromyia lanei, Psathyromyia sp (série forattiniella), Martinsmyia alphabetica, Psychodopygus arthuri, Psychodopygus lloydi, Psychodopygus ayrozai e Nyssomyia whitmani. A análise molecular baseado no gene de quitinase identificou a espécie Leishmania (L.) infantum chagasi em Pi. fischeri, Mg. migonei e Ma. alphabetica e espécies de Leishmania sp. causadoras da doença na forma tegumentar em 
Migonemyia migonei, Pintomyia fischeri, Evandromyia edwardsi, Martinsmyia alphabetica, Psychodopygus lloydi, Psychodopygus ayrozai e Nyssomyia whitmani. Os resultados obtidos alertam para o aumento do risco de transmissão das Leishmanioses e aponta para uma maior importância das medidas de vigilância entomológica, da fiscalização do uso e ocupação do solo e de estudos mais detalhados sobre as espécies desses vetores e de sua relação com os reservatórios silvestres ou urbanos e a população vulnerável no município e região.

Palavras-chave: Flebotomíneos. Leishmania. Leishmaniose tegumentar. Leishmaniose visceral. Bom Jesus dos Perdões. 


\begin{abstract}
COSTA, L. E. S. Phlebotomines diversity (Diptera, Psychodidae, Phlebotominae) and molecular detection of Leishmania species in the municipality of Bom Jesus of Pardons, state of São Paulo. [Diversidade de flebotomíneos (Diptera, Psychodidae, Phlebotominae) e detecção molecular de espécies de Leishmania no município de Bom Jesus dos Perdões, Estado de São Paulo]. 2016. 59 f. Dissertação (Mestrado em Ciências) - Faculdade de Medicina Veterinária e Zootecnia da Universidade de São Paulo, São Paulo, 2016.
\end{abstract}

Sand flies are bloodsucking Diptera belonging to the Psychodidae family and subfamily Phlebotominae. Considering the migration process of the disease in the state of São Paulo and the complexity of the relation parasite / vector / Leishmaniasis of hosts is necessary to conduct study on the ecological and epidemiological aspects of this disease. The expansion of Leishmaniasis in the interior is associated with anthropogenic processes and environmental imbalance. The municipality of Bom Jesus of Pardons goes through a growing process of urbanization which is not known to sandfly fauna as well as the search for parasites of the genus Leishmania in these vectors. This project has as main objective the identification of the sand fly fauna (Diptera, Psychodidae, Phlebotominae) and molecular detection of Leishmania species in the Municipality of Bom Jesus of Pardons, State of Sao Paulo. The sandflies were collected with CDC trap type and trap Shannon on 12 points in three different environments, and forested areas, peri-urban area and urban areas. Alpha taxonomy was based on the dichotomous key described by Galati (2003) and the name of the species were abbreviated according to Marcondes (2007). For the research of the genus Leishmania parasites were used based markers in genes SSU rDNA, cytochrome and chitinase. In the city of Bom Jesus of Pardons has recorded a wealth of 12 species of sand flies distributed into two sub-tribes: Subtribe Lutzomyiina with Migonemyia migonei, Pintomyia fischeri, Pintomyia monticola, misionensis Pintomyia, Evandromyia edwardsi and Subtribe Psychodopygina with Psathyromyia lanei, Psathyromyia sp (series forattiniella) alphabetica Martinsmyia, Psychodopygus arthuri, Psychodopygus lloydi, Psychodopygus ayrozai and Nyssomyia whitmani. Molecular analysis based on the chitinase gene identified Leishmania (L.) infantum chagasi Pi. fischeri, Mg. migonei and Ma. alphabetica and 
species of Leishmania. causing disease in cutaneous leishmaniasis in Migonemyia migonei, Pintomyia fischeri, Evandromyia edwardsi, alphabetica Martinsmyia, Psychodopygus lloydi, Psychodopygus ayrozai and Nyssomyia whitmani. The results warn of the increased risk of transmission of Leishmaniasis and points to greater importance of entomological surveillance measures, surveillance of land use and occupation and more detailed studies of the species of these vectors and their relationship to the reservoirs wild or urban and the vulnerable population in the municipality and region.

Keywords: Sand flies. Leishmania. Leishmaniasis, mucocutaneous. Visceral leishmaniasis. Bom Jesus of Pardons. 


\section{LISTA DE FIGURAS}

Figura 1 - Amastigota (medem cerca de 2 a $6 \mu \mathrm{m}$ de diâmetro)

Figura 2 - Promastigota (medem cerca de 15 a $30 \mu \mathrm{m}$ de comprimento por 2 a $3 \mu \mathrm{m}$ de diâmetro).

Figura 3 - Ciclo de vida da Leishmania spp.

24

Figura 4 - Mapa da área do Município de Bom Jesus dos Perdões 30

Figura 5 - Mapa da área do Município de Bom Jesus dos Perdões, com a localização dos pontos de coletas 


\section{LISTA DE TABELAS}

Tabela 1 - Número de espécimes capturados na borda da mata com armadilha luminosa tipo CDC, por espécie e sexo, em cada área de coleta no Município de Bom Jesus dos Perdões, no período de

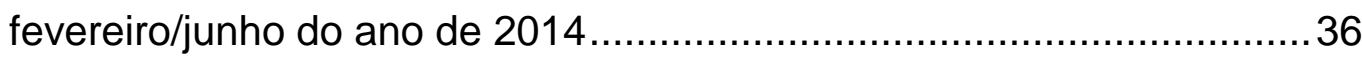

Tabela 2 - Número de espécimes capturados com armadilha de Shannon, por espécie e sexo, em cada área de coleta no Município de Bom Jesus dos Perdões, no período de fevereiro/junho do ano de 2014

Tabela 3 Número de espécimes capturados no Peridomicílio com armadilha luminosa tipo CDC, por espécie e sexo, em cada área de coleta no Município de Bom Jesus dos Perdões, no período de fevereiro/junho do ano de 2014 


\section{LISTA DE GRÁFICOS}

Gráfico 1 - Número de espécimes capturados, por espécie e sexo, no Município de Bom Jesus dos Perdões, no período de

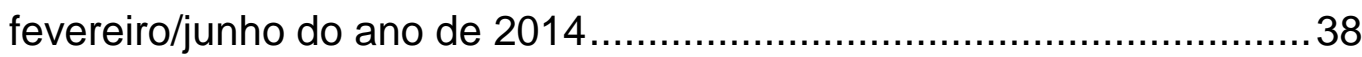

Gráfico 2 - Número de espécimes capturados, por espécie e sexo, no Município de Bom Jesus dos Perdões, no período de fevereiro/junho do ano de 2014, excluindo a espécie Pi. Fischeri..........39 


\section{SUMÁRIO}

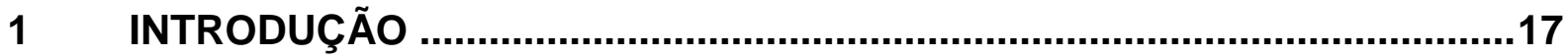

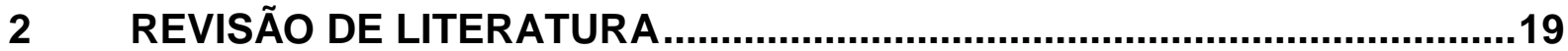

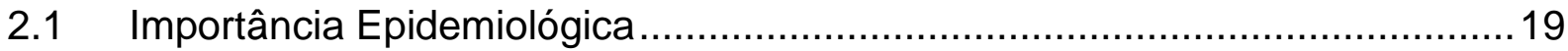

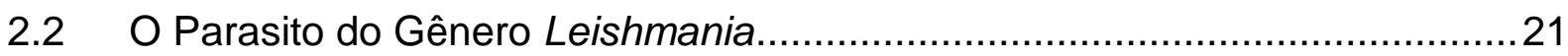

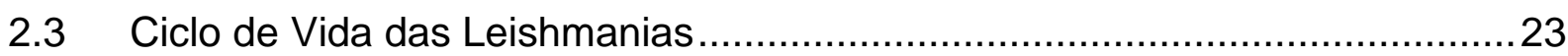

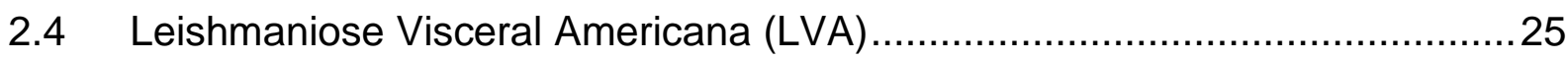

2.5 Leishmaniose Tegumentar Americana (LTA) …....................................26

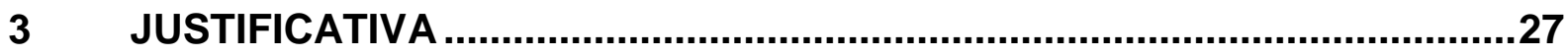

4 OBJETIVOS

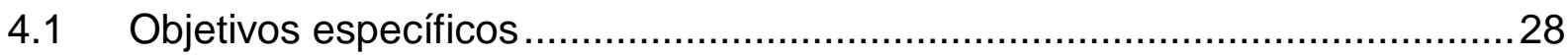

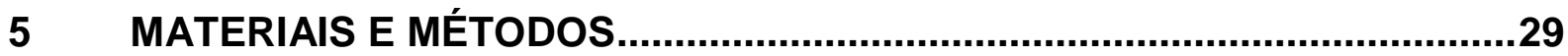

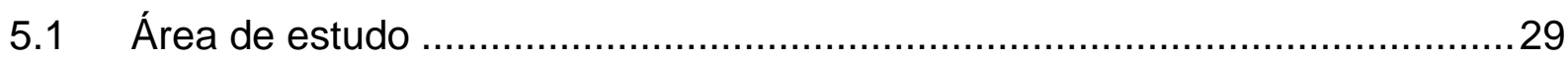

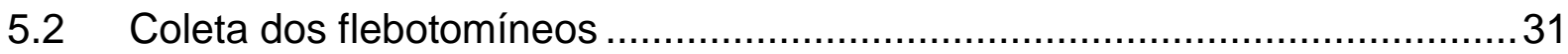

5.3 Identificação dos flebotomíneos ............................................................

5.4 Pesquisa de parasitas do gênero Leishmania...........................................33

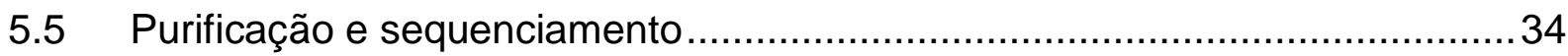

5.6 Análise da preferência alimentar dos flebotomíneos capturados...................34

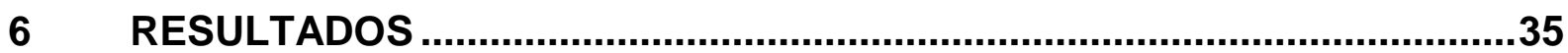

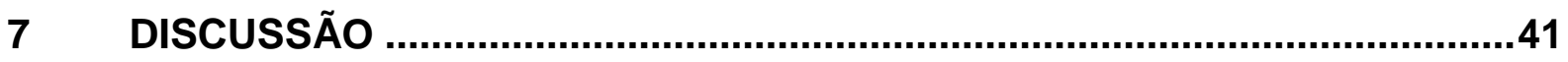

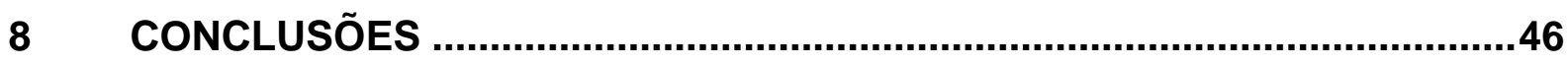

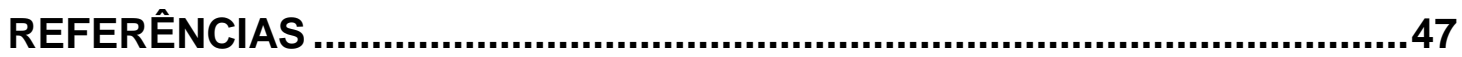




\section{INTRODUÇÃO}

Os flebotomíneos, assim como a generalidade dos dípteros, são insetos holometabólicos, suas formas imaturas têm habitat terrestre, desenvolvendo-se em locais ricos em matéria orgânica em decomposição, especialmente de natureza vegetal (MEDEIROS 2003).

Os adultos são amarelados, muito pequenos, com cerca de $2,5 \mathrm{~mm}$ de comprimento, as pernas são longas e delgadas, possuem voo saltitante e quando em repouso mantêm as asas eretas, que são hialinas e densamente revestidas de cerdas longas (AGUIAR et al., 1987). A superfície corporal é bastante permeável, pois apresenta um revestimento quitinoso delgado, necessitando, assim, "abrigar-se em locais onde possa proteger-se das mudanças bruscas que ocorrem no meio ambiente" (AGUIAR et al., 1987).

No Brasil, dependendo da região geográfica, os flebotomíneos são conhecidos popularmente, como tatuquira, asa dura, asa branca, mosquito palha, birigui, cangalinha, anjinho (CARREIRA-ALVES, 2008).

Os flebotomíneos distribuem-se por quase todas as regiões do mundo, sendo mais abundantes na Região Neotropical, com maior número de espécies e densidade que flutuam de acordo com a estação climática (SHERLOCK, 2003).

Shimabukuro \& Galati (2011) relatam que em todo o mundo são conhecidas, aproximadamente, 900 espécies de flebotomíneos, das quais, mais de 500 estão presentes na região Neotropical.

Distintamente do que ocorre na região noroeste do Estado de São Paulo, onde a transmissão da leishmania visceral americana (LVA) se dá em ambiente urbano consolidado, na região da Grande São Paulo, a ocorrência tem sido associada a áreas com presença de matas residuais em uma transição entre urbano e rural, ou mesmo rural (GALVIS OVALLOS, 2011).

Aguiar e Medeiros (2003) sugeriram categorizar as 260 espécies de flebotomíneos brasileiros em três grupos de acordo com seu atual comportamento: silvestres, semi-domésticos e domésticos. Para realizar esta distribuição eles observaram que algumas espécies ainda vivem exclusivamente em áreas florestais 
ou até não florestais, mas só encontram-se associadas a homens e animais domésticos acidentalmente.

Estas espécies foram classificadas como silvestres, que envolvem 147 (56\%) (SHIMABUKURO; GALATI, 2011) das espécies relatadas no Brasil. As semidomésticas, foram assim classificadas, pois vivem fora das habitações humanas e animais, mas adentram estes ambientes para o repasto sanguíneo. Por sua vez, as espécies classificadas como domésticas vivem associadas ao homem e aos animais, no interior ou muito próximo de suas habitações. (SHIMABUKURO; GALATI, 2011) 


\subsection{Importância Epidemiológica}

Mais de 33 espécies de flebotomíneos estão relacionadas com a transmissão de agentes de doenças a humanos (CÁCERES, 1993). Mas apesar de já esclarecido, permanece pouco divulgado que eles também estão envolvidos no ciclo de outras enfermidades como a reação de urticaria local denominada Harara, e a competência para transmitir tripanossomatídeos para répteis e anfíbios.

Pintomyia verrucarum é uma espécie peridomiciliar de flebotomíneo, cuja presença está relacionada com as áreas de ocorrência da doença de Carrión. Também conhecida como febre de Oroya, bartonelose ou verruga peruana, esta doença é causada pela bactéria Bartonella baciliformis e cursa com casos de severa hemólise, que pode gerar severa infecção secundária e levar a morte (CÁCERES, 1993).

Como citado, os flebotomíneos também são vetores de tripanossomatídeos. $\mathrm{Na}$ ilha de Malta, três exemplares de Sergentomyia minuta se infectaram intensivamente com Trypanosoma platydactylis após se alimentarem em um lagarto da espécie Tarentola mauritanica. Na Índia, Trypanosoma phlebotomi foi encontrado sendo transmitido por Sergentomyia babu shorttii; e na China Sergentomyia squamirostris é a espécie vetor de Trypanossoma bocagei, que é um parasito do anfíbio Bufo bufo gargarisans (ADLER; THEODOR, 1957).

Em geral, entre as doenças transmitidas por flebotomíneos, a leishmaniose assume um destaque impar. Antes de conhecer o vetor da leishmaniose, os pesquisadores procuraram nos insetos, a habilidade deles cumprirem com duas exigências: a primeira é que o vetor deveria estar presente na área de prevalência das doenças, e a segunda é que o vetor proposto deveria possuir um trato alimentar estéril (ADLER; THEODOR, 1957). Mais tarde, novas características ajudaram a sedimentar este inquérito, pois identificaram capacidade parasitária de resistir às atividades das enzimas digestivas do inseto, capacidade parasitária de escapar do bolo alimentar e aderir ao epitélio intestinal durante a excreção do mesmo, completar 
seu ciclo de vida e serem inoculados em um hospedeiro vertebrado (PIMENTA et al., 2003).

As formas clínicas de leishmaniose humana conhecidas no mundo são: visceral, muco-cutâneo, cutâneo-difusa e cutânea (DESJEUX, 2004). No entanto, apenas duas denominações são utilizadas no Brasil: Leishmaniose Visceral Americana (LVA) e Leishmaniose Tegumentar Americana (LTA), onde esta última engloba as diferentes formas clínicas causadas pelas Leishmanias dermotrópicas (ALVES, 2005).

A forma de expressão clínica de leishmaniose no animal vertebrado vai depender do tipo de Leishmania infectante, de fatores genéticos do hospedeiro, e da espécie vetora, pois os flebotomíneos possuem distribuição, hábitos alimentares e outros aspectos individuais (REYES-URIBE et al., 2012).

A leishmaniose visceral na América, segundo Shaw (2007) e Marcili et al. (2014) é causada pela Leishmania (Leishmania) infantum chagasi, possui a Lutzomyia longipalpis como o principal vetor, podendo ser encontrado desde o México à Argentina. Ao norte da Colômbia e Venezuela, Pintomyia evansi é quem atua como o principal vetor em áreas onde a Lutzomyia longipalpis não está presente ou apresenta baixa densidade.

Camargo-Neves (2006), relata que, no Brasil, as principais espécies envolvidas na transmissão da Leishmaniose Tegumentar Americana são: Bichromomyia flaviscutellata, Nyssomyia whitmani, Nyssomyia umbratilis, Nyssomyia intermedia, Psychodopygus wellcomei e Migonemyia migonei. Cabe ressaltar que o papel vetorial de cada uma dessas espécies dependera da espécie de Leishmania presente no intestino. Embora ainda não tenha sido comprovado o papel da Nyssomyia neivai e Pintomyia fisheri como vetores da LTA, estas espécies têm sido encontradas com frequência em ambientes domiciliares em áreas de transmissão da doença.

Shimabukuro e Galati (2011) registraram no estado de São Paulo 22 gêneros de flebotomíneos, que se traduzem em 75 espécies de flebotomíneos identificados, incluindo três espécies vetoras da leishmaniose tegumentar (Nyssomyia intermedia, Nyssomyia neivai e Nyssomyia whitmani) e uma espécie vetora da leishmaniose visceral americana (Lutzomyia longipalpis).

Além disso, há evidências de que a LVA já se expandiu ao longo das rotas da atividade humana em direção a oeste e centro-oeste do Estado de São Paulo, 
afetando, principalmente, mas não exclusivamente, as cidades perto da rodovia Marechal Rondon. Consequentemente, casos autóctones de LVA humana foram registrados em cidades ao longo dessas vias, como nas seguintes cidades: Araçatuba (1999), Penápolis (2001), Bauru (2003), Agudos (2006) e Lençóis Paulista (2007) (CUTOLO et al., 2013).

Em Campinas, no final do ano de 2009, foi confirmado o primeiro caso de LVA canino autóctone em área de proteção ambiental na região leste da cidade (VON ZUBEN, 2014).

Segundo Casanova et al., 2015, com base em estudos genéticos e comportamentais é aceito que o L. longipalpis é uma espécie complexa, mas não está claro quantos membros existem e como eles estão relacionados. Também aponta a existência de dois padrões epidemiológicos distintos de LVA no Estado de São Paulo e a existência de duas populações L. longipalpis com diferente capacidade vetorial.

\subsection{O Parasito do Gênero Leishmania}

Os agentes etiológicos das leishmanioses são os protozoários tripanosomatídeos do gênero Leishmania que pertencem ao filo Sarcomastigophora, ordem Kinetoplastida e família Trypanosomatidae (ROSS, 1903; CHANCE,1985).

São organismos unicelulares com uma organela especializada denominada cinetoplasto e requerem a participação de mais de um hospedeiro para completar o ciclo biológico (FOCACCIA, 2010).

Estes protozoários apresentam duas formas morfológicas distintas durante seu ciclo: amastigota e promastigota (Figuras 1 e 2 ). As leishmanias são encontradas no tubo digestivo dos flebotomíneos (fêmeas) em sua forma promastigota (flagelada) e são parasitas intracelulares obrigatórios das células do Sistema Fagocítico Mononuclear (SFM) dos vertebrados na sua forma amastigota (forma oval ou esférica, sem flagelo aparente).

Nos hospedeiros vertebrados destes protozoários, pertencentes a várias ordens e espécies, os parasitos assumem a forma amastigota, arredondada e 
imóvel, que se multiplica obrigatoriamente dentro de células do SFM e na medida em que as formas amastigotas vão se multiplicando, os macrófagos se rompem, liberando parasitos que são fagocitados por outros macrófagos (ALVAR et al., 2012).

Ao realizarem o repasto sanguíneo a partir de indivíduos portadores de alguma espécie de leishmânia, os flebotomíneos ingerem células do sangue contendo parasitos.

Figura 1 - Amastigota (medem cerca de 2 a $6 \mu \mathrm{m}$ de diâmetro)

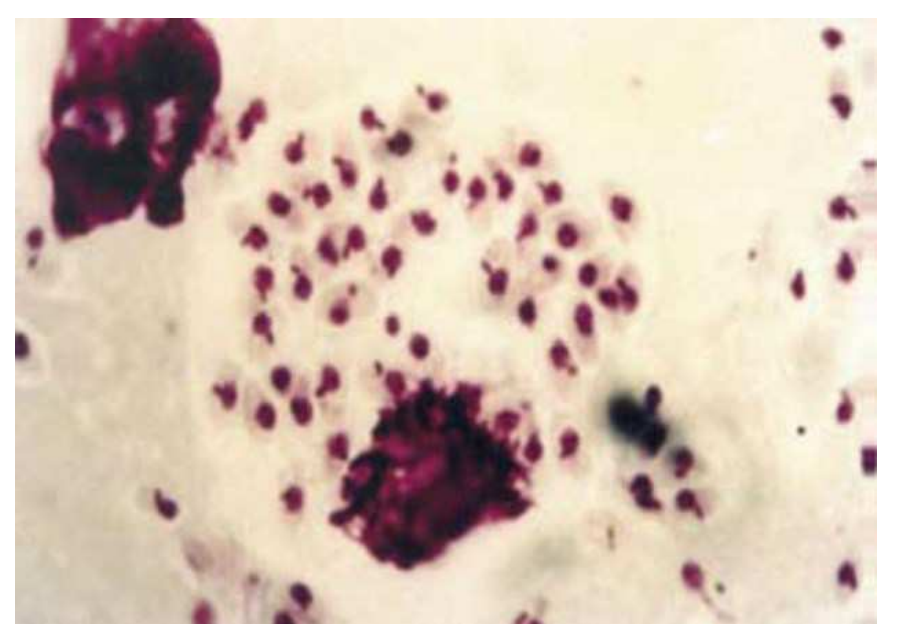

Fonte: http://www4.ensp.fiocruz.br/Leishmaniose/lt/definicoes/

Figura 2 - Promastigota (medem cerca de 15 a $30 \mu \mathrm{m}$ de comprimento por 2 a 3 um de diâmetro)

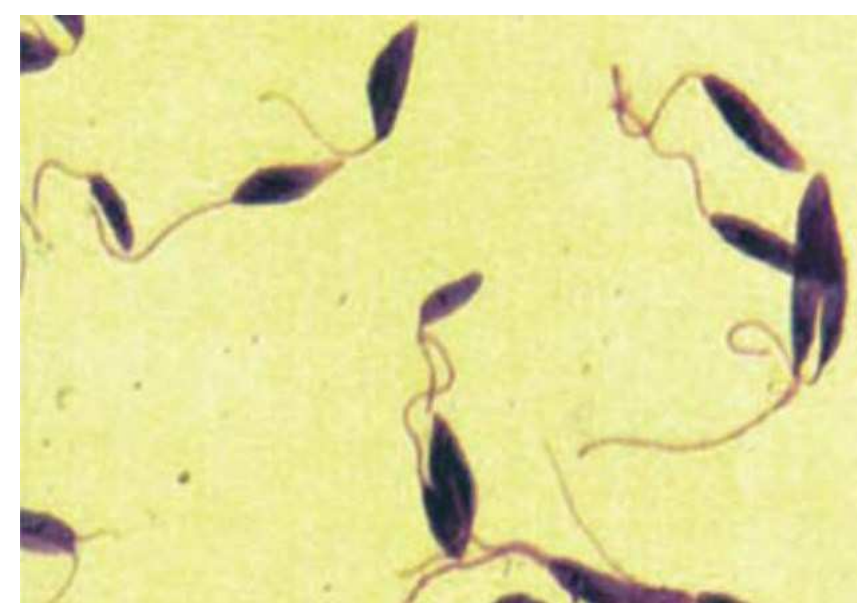

Fonte: http://www4.ensp.fiocruz.br/Leishmaniose/lt/definicoes/

Atualmente são conhecidas cerca de trinta espécies de Leishmania que infectam mamíferos, agrupadas e classificadas em dois subgêneros: o subgênero $L$. (Leishmania) e L. (Viannia) (LAINSON, 1985; WHO, 2010). 
De acordo com esta classificação, as espécies pertencentes ao subgênero Leishmania desenvolvem-se de forma exclusiva na porção média e anterior do intestino (seção Suprapilaria), enquanto as espécies do subgênero Viannia desenvolvem-se nas partes anterior e média, assim como no intestino posterior na região do piloro (seção Peripilaria) dos flebotomíneos (LAINSON, 1979).

Os parasitos de répteis foram agrupados em um novo gênero: Sauroleishmania (RANQUE et al., 1973; KILLICK-KENDRICK et al., 1986).

\subsection{Ciclo de Vida das Leishmanias}

As fêmeas de flebotomíneos ingerem os macrófagos com as formas amastigotas através do sangue ou linfa intersticial durante o repasto sanguíneo em animais vertebrados hospedeiros de Leishmanias infectados (DIAS, 2015). No tubo digestivo destes insetos, os macrófagos são lisados e as amastigotas liberadas e dividem-se ao menos uma vez antes de transformarem-se em promastigotas (DIAS, 2015).

As formas reprodutivas não infectantes prendem-se à parede do tubo digestivo após atravessarem a matriz peritrófica, onde sofrem o ataque das enzimas digestivas. É então desencadeada uma metaciclogênese, processo no qual estas formas deixam de se reproduzir e tornam-se infectantes, ocorrendo à transformação nas formas promastigotas metacíclicas (formas infectivas). Durante a metaciclogênese, as promastigotas sofrem modificações bioquímicas em sua superfície e perdem sua capacidade de adesão ao epitélio do intestino médio dos flebotomíneos. Estas formas promastigotas metacíclicas, então, migram para a faringe e cavidade bucal e são encontradas livres ou aderidas na porção anterior do aparelho bucal (proventrículo e faringe) do inseto e são transmitidas ao hospedeiro vertebrado durante o próximo repasto sanguíneo (DIAS, 2015).

As formas promastigotas metacíclicas se concentram na região da válvula estomodeal (cárdia) promovendo sua destruição, que acontece devido à degradação de uma camada de quitina que reveste esta porção do intestino do inseto através da liberação de quitinase, produzida pelo próprio parasito (SCHLEIN; JACOBSON; MESSER, 1992). 
A destruição da válvula faz com que o flebotomíneo regurgite no local da picada, ao realizar o repasto sanguíneo no animal vertebrado, o conteúdo intestinal da porção anterior do tubo digestivo (cárdia e probóscide) com as promastigotas metacíclicas, podendo infectar o hospedeiro vertebrado. Estas formas flageladas são fagocitadas inicialmente por neutrófilos e eosinófilos e depois por macrófagos e células dendríticas (POLI et al., 2002; BANETH et al., 2008).

Dentro dos vacúolos dos macrófagos, as formas promastigotas diferenciamse em amastigotas e multiplicam-se por divisão binária. O núcleo do macrófago chega a deslocar-se do centro para dar lugar ao vacúolo com as formas amastigotas, esgotando-se sua resistência e levando ao seu rompimento; as amastigotas liberadas devido ao rompimento dos macrófagos são fagocitadas por outros macrófagos (PENNA, 1934).

O ciclo continua quando flebotomíneos realizam repasto sanguíneo em animais vertebrados portadores de Leishmanias e são infectados, transmitindo-as a novos hospedeiros vertebrados (Figura 3).

Figura 3 - Ciclo de vida da Leishmania spp.

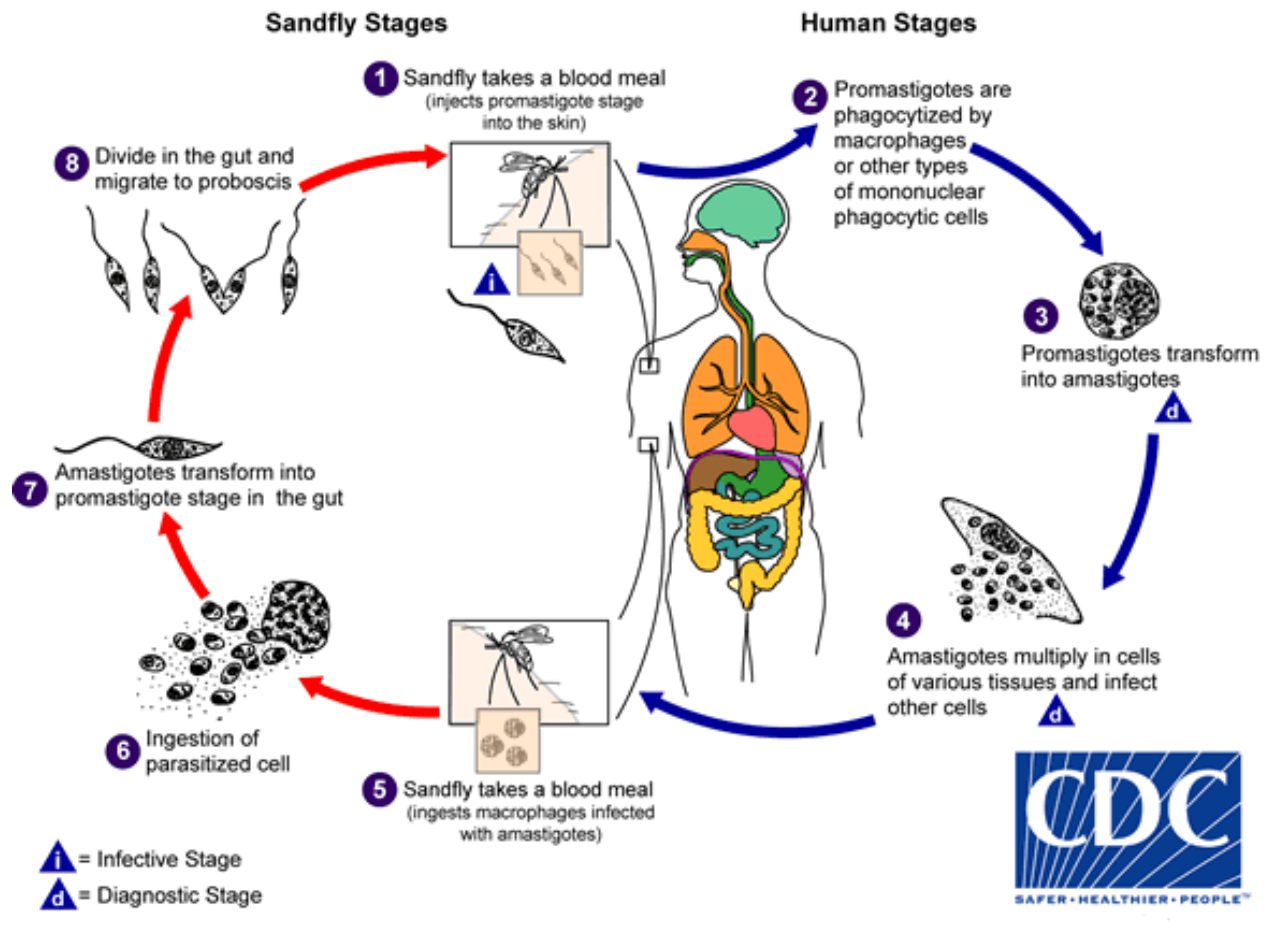

Fonte: www.cdc.gov 


\subsection{Leishmaniose Visceral Americana (LVA)}

A leishmaniose visceral americana é a mais grave das leishmanioses, podendo ser fatal se não tratada. Pode haver pacientes assintomáticos, oligossintomáticos (manifestações clínicas discretas) que evoluem para cura espontânea, e oligossintomáticos que evoluem para a forma clássica da doença. Sua manifestação clínica está associada à desnutrição nos pacientes desnutridos, a forma clássica da doença da LVA é frequente (BRASIL, 2013).

O período de incubação é bastante variável; em humanos o período é de 10 dias a 24 meses, com média entre 2 a 6 meses e em cães é de 3 meses a vários anos, com média de 2 a 7 meses (BRASIL, 2014).

Nos casos clínicos, os principais sintomas apresentados são: febre prolongada e intermitente, emagrecimento, hepatoesplenomegalia, anemia severa, leucopenia, hipergamaglobulinemia, tosse, dor abdominal, diarreia, perda de peso devido à perda de apetite e caquexia. Também pode ocorrer um complexo de manifestações imunomediadas, como uveíte e nefrite (DIAS, 2015).

No Novo Mundo, a Leishmania (L.) infantum chagasi é o agente etiológico da LVA. São duas as espécies de flebotomíneos vetores conhecidos da LVA no Brasil: Lutzomyia cruzi e Lutzomyia longipalpis, sendo esta última mais amplamente dispersa pelo país (DIAS, 2015).

Segundo Casanova et al., 2015, com base em estudos genéticos e comportamentais é aceito que o L. longipalpis é uma espécie complexa, mas não está claro quantos membros existem e como eles estão relacionados. Também aponta a existência de dois padrões epidemiológicos distintos de LVA no Estado de São Paulo e a existência de duas populações L. longipalpis com diferente capacidade vetorial.

Entretanto, em algumas áreas endêmicas de LVA não são encontradas nenhuma destas duas espécies. Os principais hospedeiros silvestres da $L$. (L.) infantum chagasi conhecidos são as raposas e os marsupiais, sendo os cães considerados importantes hospedeiros domésticos (MAURICIO et al., 1999; KUHLS et al., 201; MARCILI et al., 2014). 
2.5 Leishmaniose Tegumentar Americana (LTA)

Segundo Goto \& Lauletta Lindoso (2015) as leishmanioses tegumentares podem apresentar várias formas clínicas que dependem da espécie da Leishmania que está envolvida, bem como a resposta do hospedeiro. A lesão inicial é no local da picada do vetor sob a forma de uma mácula, a qual a partir de 2 semanas a 3 meses em diante podendo se apresentar como uma pequena pápula eritematosa e / ou nódulo, podendo evoluir para um granuloma. Esta lesão pode resolver espontaneamente ou pode evoluir para uma úlcera característica e algumas lesões podem, em seguida, evoluir para formas crônicas.

Com base nas suas diferentes manifestações clínicas a leishmaniose tegumentar é classificada como leishmaniose cutânea localizada (LCL), leishmaniose cutânea difusa (DCL), leishmaniose disseminada, leishmaniose recidiva (LR) e leishmaniose mucosa. $A$ LCL é a forma mais prevalente e é causada por todas as espécies de Leishmania dermotrópicas. O tipo de lesão mais comum é caracterizado por uma úlcera e pode variar desde 1 a 10 lesões que estão localizadas numa área exposta do corpo. Normalmente, a úlcera é indolor, rosa, e redonda, com bordas bem delimitadas, um endurecimento da base, e um fundo limpo, onde às vezes pode aparecer uma crosta central que pode sangrar.

A resolução espontânea pode ocorrer, deixando uma cicatriz hipopigmentada, lisa e fina, no entanto, alguns casos podem evoluir para outras formas da doença (GOTO, et al., 2015).

Os principais agentes etiológicos da LTA nas Américas são as espécies: Leishmania (L.) braziliensis, L. (L.) amazonensis, L. (L.) guyanensis, L. (L.) lainsoni e L. (L.) panamensis (PIRMEZ et al., 1993; DA-CRUZ et al., 1994; CARVALHO et al., 1995; COUTINHO et al., 1996). 


\section{JUSTIFICATIVA}

O estudo da distribuição e ecologia das espécies de flebotomíneos é essencial para a vigilância epidemiológica e para estimar o risco de transmissão de diferentes espécies de Leishmania e Trypanosoma, observando as características ambientais propícias para a sua proliferação. O município de Bom Jesus dos Perdões apresenta 63\% de Mata Atlântica, a maioria dentro do Parque Estadual da Serra do Itapetinga, localizado entre a Serra da Cantareira e a Serra da Mantiqueira, e está localizado a 70 km município de Campinas, onde já ocorrem casos autóctones caninos.

O município de Bom Jesus dos Perdões é área endêmica para Leishmaniose Tegumentar e é classificado pela Secretaria Estadual de Saúde e SUCEN, como município silencioso não receptivo vulnerável para a Leishmaniose Visceral, ou seja, não apresenta casos autóctones humanos ou caninos da doença, sem a presença conhecida do vetor e selecionada pelos valores de distância estimados para caracterizar a vulnerabilidade. Porém, o município apresenta um crescente processo de urbanização, o transito de pessoas e cães, um grande desequilíbrio ambiental, a ocupação de áreas silvestres pelo homem e uma maior exposição de pessoas aos vetores.

Considerando a complexidade da relação parasito/vetor/hospedeiros da Leishmaniose é necessário realizar estudo sobre a fauna Flebotomínica e seus aspectos ecológicos no município de Bom Jesus dos Perdões, para implementação de medidas de Vigilância Epidemiológicas, como a vigilância entomológica. 


\section{OBJETIVOS}

O presente projeto tem por objetivo principal, a identificação da fauna de Flebotomíneos (Diptera, Psychodidae, Phlebotominae) e detecção molecular de parasitas do gênero Leishmania nestes vetores capturados no município de Bom Jesus dos perdões, estado de São Paulo.

\subsection{Os objetivos específicos}

1. Estudar a fauna de flebotomíneos em áreas de Mata, Periurbana e Urbana no município de Bom Jesus dos Perdões no estado de São Paulo;

2. Detecção molecular de parasitas do gênero Leishmania nos flebotomíneos coletados em áreas de Mata, Periurbana e Urbanas no município de Bom Jesus dos Perdões no estado de São Paulo;

3. Analisar a preferência alimentar das espécies de flebotomíneos capturadas através de estudos moleculares baseados no gene de citocromo B. 


\section{MATERIAIS E MÉTODOS}

5.1 Área de estudo

O município de Bom Jesus dos Perdões faz fronteira com o município de Atibaia, de Nazaré Paulista e de Piracaia onde se encontram as represas do Sistema Cantareira que abastece a região e a grande parte da metrópole de São Paulo (PLANO MUNICIPAL DE DESENVOLVIMENTO RURAL DE BOM JESUS DOS PERDÕES, 2010 - 2013).

Possui características climáticas tipo Cwb (tropical de altitude) - os totais de chuva, nessa mesorregião variam de 1.300 a 1.700 mm anuais, no sentido lesteoeste. As temperaturas médias variam em função, principalmente, da altitude e da latitude do lugar. As menores temperaturas médias mensais ocorrem entre Maio e Setembro, com mínima em Julho (mínima de $15,9^{\circ} \mathrm{C}$ ), caracterizando uma atmosfera estável e com temperaturas abaixo da média anual.

Já nos outros meses, ocorrem temperaturas médias mensais acima da média anual. Sendo as maiores situadas entre Janeiro à Março (com máxima de $22,3^{\circ} \mathrm{C}$ em fevereiro), o que caracteriza uma atmosfera instável, favorecendo a circulação de ar (PLANO MUNICIPAL DE DESENVOLVIMENTO RURAL DE BOM JESUS DOS PERDÕES, 2010 - 2013).

Apresenta uma temperatura média de $19,1^{\circ} \mathrm{C}$. As serras existentes no município fazem parte dos primeiros contrafortes da Serra da Mantiqueira, e localizam-se, preferencialmente, nas porções leste-sul, recebendo denominação de Serra do Itapetinga, onde o afloramento de rochas é bastante comum (PLANO MUNICIPAL DE DESENVOLVIMENTO RURAL DE BOM JESUS DOS PERDÕES, 2010 - 2013).

O município de Bom Jesus dos Perdões é cortado pela Rodovia Dom Pedro I, rodovia que liga a região de Campinas ao Vale do Paraíba, ficando, portanto na rota da expansão da Leishmaniose e classificado pela Secretaria Estadual de Saúde e pela SUCEN (Superintendência de Controle de Endemias), como município silencioso não receptivo vulnerável. Portanto, o município de Bom Jesus dos 
Perdões sem a confirmação de casos autóctones de leishmaniose visceral em humanos e caninos, sem a presença conhecida do vetor e selecionada pelos valores de distância estimados para caracterizar a vulnerabilidade.

Bom Jesus dos Perdões apresenta grande parte de sua área com presença de Mata Atlântica, a maior parte dentro do Parque Estadual da Serra do Itapetinga, localizado entre a Serra da Cantareira e a Serra da Mantiqueira.

Figura 4 - Mapa da área do Município de Bom Jesus dos Perdões

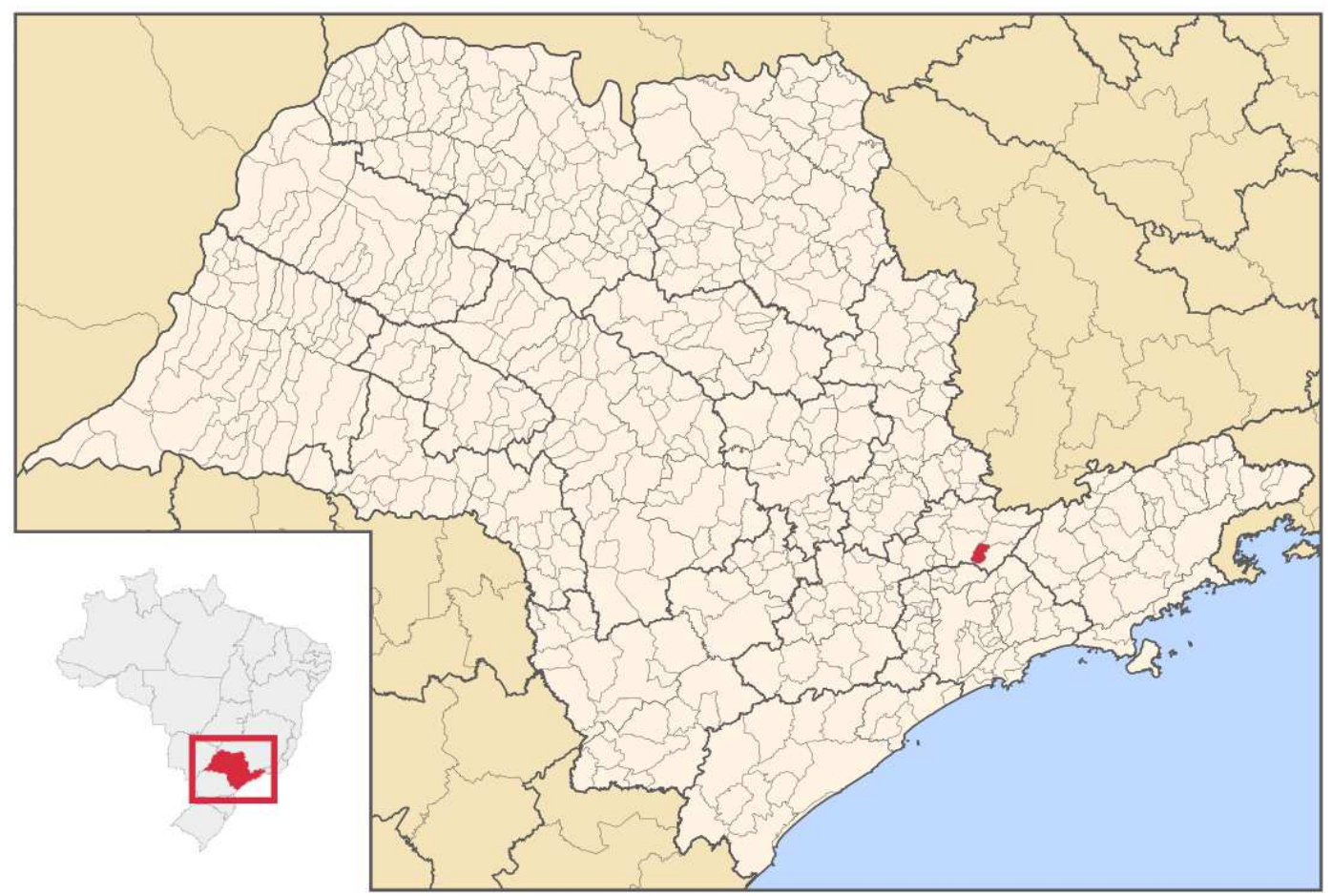

Fonte: https://pt.wikipedia.org/

Com relação à diversidade biológica e presença de espécies ameaçadas, os dados disponibilizados por Pellin (2010) para a referida área relacionam a existência de 147 espécies de flora nativa, das quais sete sofrem algum tipo de ameaça estadual (São Paulo), nacional (IBAMA) ou mundial (IUCN); 88 espécies de avifauna, das quais 30 são endêmicas da Mata Atlântica, 10 são consideradas raras ou incomuns e uma sofre ameaça de extinção e 33 espécies de mamíferos (considerando o Parque e seu entorno) das quais três são endêmicas, o bugio (Alouatta clamitans), o sauá (Callicebus nigrifons) e o sagui-da-serra-escuro (Callithrix aurita) e 29 se encontram em alguma categoria de ameaça ou são consideradas como dados deficientes, seja pelo estado, país ou a nível mundial. 


\subsection{Coleta dos flebotomíneos}

As coletas foram efetuadas de Fevereiro a Junho de 2014, empregando duas técnicas de capturas: armadilhas automáticas luminosas tipo CDC e armadilhas Shannon. As armadilhas luminosas tipo CDC foram construídas seguindo o modelo de Natal et al., (1991), com uma bateria de 6 voltz como fonte de energia e armadilha do tipo Shannon modificada na cor branca (GALATI et al., 2001).

Foram utilizadas duas armadilhas luminosas por coleta, instaladas na borda da mata a 1,5 $\mathrm{m}$ do solo e no peridomicílio das casas, preferencialmente, próximas de canis, galinheiros, pocilgas ou currais, nas áreas 9, 11 e 12 foi utilizada somente uma CDC por coleta. As capturas com essas armadilhas luminosas deram início as 18:00h e se estenderam por um período de 12 horas, até as 06:00h do dia seguinte.

A armadilha do tipo Shannon era instalada aproximadamente a $20 \mathrm{~m}$ dentro da mata a 1,5 $\mathrm{m}$ do solo e as capturas deram início as 18:00h se estendendo por um período de 04 horas, até as 22:00h, foram realizadas 9 coletas utilizando esse tipo de armadilha, pois não foi possível utiliza-las no ecótopo urbano, áreas 9, 11 e 12.

O esforço de captura foi de 216 horas trabalhadas nos ecótopos de mata e periurbano (áreas 1, 2, 3, 4, 5, 6, 7, 8 e 10), utilizando a armadilha tipo CDC, sendo 24 horas em cada área. No ecótopo urbano (áreas 9, 11 e 12) o esforço foi de 36 horas trabalhadas, sendo 12 horas por área. Para a armadilha tipo Shannon utilizada nos ecótopos de mata e periurbano (áreas $1,2,3,4,5,6,7,8$ e 10), o esforço de captura foi de 36 horas trabalhadas, sendo 4 horas por área.

Os flebotomíneos coletados foram transferidos para uma gaiola entomológica.

As capturas ocorreram em 03 ecótopos: Área de Mata, Área periurbana e Área Urbana. 
Figura 5 - Mapa da área do Município de Bom Jesus dos Perdões, com a localização dos pontos de coletas

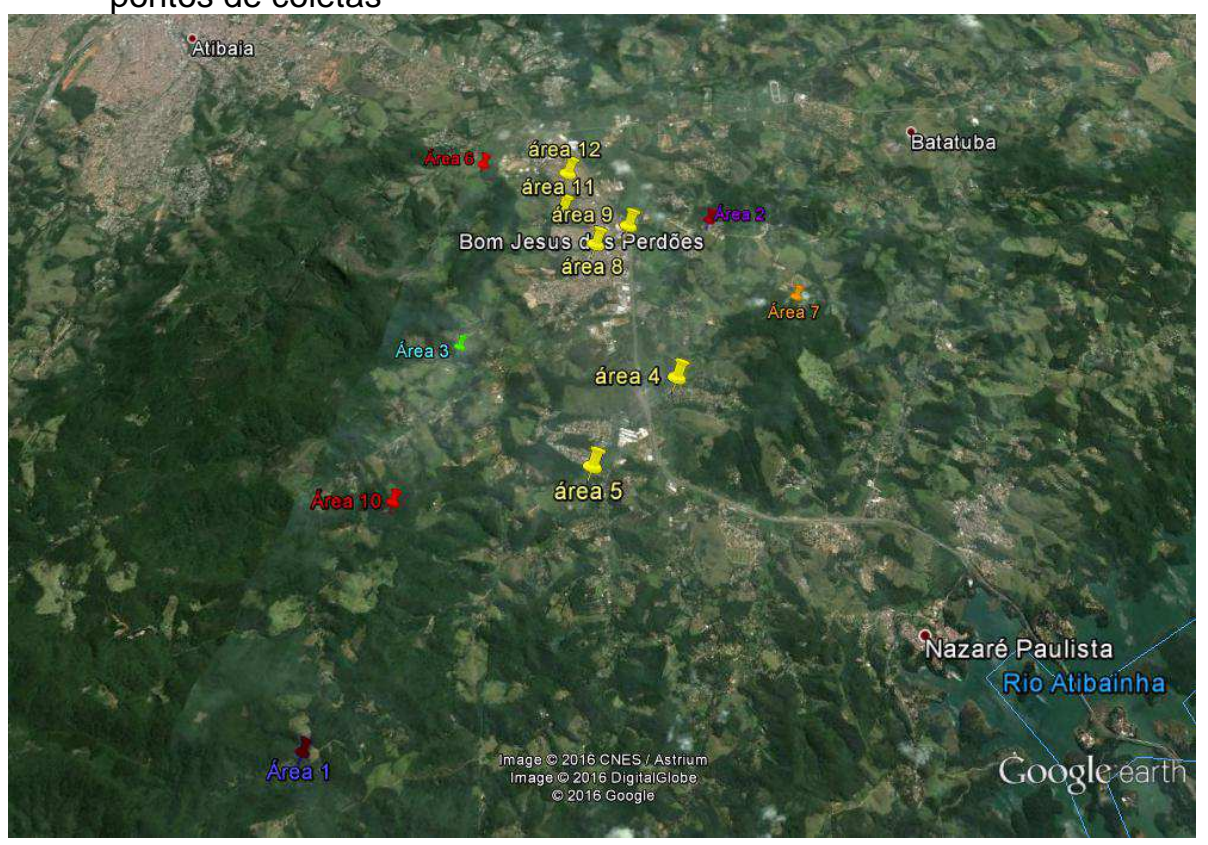

Fonte: earth.google.com.br

As áreas de Mata se localizavam principalmente dentro do Parque Estadual do Itapetinga, com a característica de mata fechada e pouca presença do homem, as áreas Periurbanas se caracterizavam em bolsões de matas e capoeiras, com a presença de pequenas comunidades e animais domésticos, como cães, gatos, galinhas, vacas, cavalos, porcos e ovelhas. Já as áreas urbanas se caracterizavam pela pequena presença de vegetação e pela intensa presença humana e de animais domésticos, principalmente cães, gatos e aves, como galinhas.

Essa pesquisa foi submetida ao CEUA - Comissão de Ética no Uso de Animais da Faculdade de Medicina Veterinária e Zootecnia - Universidade de São Paulo.

5.3 Identificação dos flebotomíneos

Os flebotomíneos coletados foram transportados para o Laboratório da Unidade de Vigilância de Zoonoses (UVZ) da Secretaria de Saúde de Bom Jesus dos Perdões e alguns exemplares coletados, também foram levados para o Laboratório 
de Entomologia de Saúde Pública/Phlebotominae da Faculdade de Saúde Pública, Universidade de São Paulo.

Todos os flebotomíneos coletados foram clarificados segundo Forattini (1973) e identificados em nível de espécie seguindo Galati (2003, 2011).

Foram analisados sob microscopia óptica os caracteres: cabeça e seus apêndices, cervix, tórax, abdômen e genitália dos machos e somente cabeça e seus apêndices e genitálias (localizada na porção final do abdômen) nas fêmeas, pois o restante do espécime foi preservado em etanol 100\% (Merck) para a extração de DNA.

Após a identificação, alguns exemplares de cada espécies amostrada será depositados na Coleção Biológica do Instituto Butantã e os demais exemplares preservados em etanol 100\% (Merck) para a extração de DNA.

\subsection{Pesquisa de parasitas do gênero Leishmania}

Os exemplares mantidos em etanol foram submetidos à extração de DNA de acordo com o protocolo estabelecido pelo Kit Wizard SV Clean up ® (Promega, Wisconsin, USA). As amostras foram separadas em pools de até 12 indivíduos de cada espécie, por área de coleta e tipo de armadilha

Para a detecção e identificação das espécies de Leishmania foi utilizado o gene da quitinase (SUZUKI et al., 2015). Este gene possui função essencial no gênero Leishmania, sendo conservado no grupo, e ausente em outros grupos de tripanossomatídeos. Além disso, estudos iniciais demonstraram alta sensibilidade e especificidade do gene que codifica a quitinase de Leishmania infantum chagasi em ensaios de detecção molecular por PCR a partir de diferentes amostras clínicas de humanos e cães. A literatura indica que as quitinases de Leishmania, assim como as de outros protozoários patogênicos, podem facilitar a infecção parasitária como a sobrevivência dos protozoários dentro de seus hospedeiros invertebrados (SCHLEIN; JACOBSON; SHLOMAI, 1991). Além disso, foi sugerido que as quitinases também participariam da transmissão desses organismos aos seus 
hospedeiros mamíferos (JOSHI et al., 2005; ROGERS et al., 2008). Assim, para a detecção molecular de parasitas do gênero Leishmania nos flebotomíneos capturados na área de estudo foi utilizado o gene da quitinase como alvo (SUZUKI et al., 2015).

Os pools positivos na análise molecular para Leismania spp através o gene de quitinase foram submetidos ao PCR para os alvos SSU rDNA e Citocromo b (MAIA DA SILVA et al., 2004, 2007; HAMILTON et al., 2004, 2007, 2009; RODRIGUES et al., 2006; MARCILI et al., 2009a, b, c).

A taxa de infecção natural foi expressa como taxa mínima de infecção (TMI), calculada dividindo-se o número de grupos positivos pelo número total de espécimes testados x 100 (PAIVA et al, 2007).

5.5 Purificação e sequenciamento

Fragmentos de DNA amplificados por PCR (produtos amplificados em três reações independentes) foram separados por eletroforese em gel de agarose a $2 \% \mathrm{e}$ corados com Gel-Red (Biotium). Os fragmentos foram cortados dos géis e os DNAs purificados através do kit EXOSAP (Afemetrix). Os produtos purificados foram sequenciados ou submetidos diretamente à reação de seqüenciamento. Os fragmentos purificados foram submetidos a reações de seqüenciamento utilizando o kit Big Dye Terminator (Perkin Elmer), de acordo com especificações do fabricante, em seqüenciador automático ABI PRISM 3100 Genetic Analyzer (Perkin Elmer).

5.6 Análise da preferência alimentar dos flebotomíneos capturados

Os lotes para as diferentes espécies de Leishmania spp foram submetidos a PCR para analisar a preferência alimentar das espécies de flebotomíneos capturados através da amplificação e sequenciamento do gene de citocromo $B$ de vertebrados. 
No município de Bom Jesus dos Perdões foram capturados 878 flebotomíneos, pertencentes a 12 espécies e distribuídas em duas subtribos.

Subtribo Lutzomyiina

Migonemyia migonei (FRANÇA, 1920);

Pintomyia fischeri (PINTO, 1926);

Pintomyia monticola (COSTA LIMA, 1932);

Pintomyia misionensis (CASTRO, 1959);

Evandromyia edwardsi (MANGABEIRA, 1941).

Subtribo Psychodopygina

Psathyromyia lanei (BARRETO; COUTINHO, 1940);

Psathyromyia sp (série forattiniella) (VARGAS, 1978);

Martinsmyia alphabetica (FONSECA, 1936);

Psychodopygus arthuri (FONSECA, 1936);

Psychodopygus Iloydi (ANTUNES, 1937);

Psychodopygus ayrozai (BARRETO; COUTINHO, 1940);

Nyssomyia whitmani (ANTUNES; COUTINHO, 1939).

$\mathrm{Na}$ borda de mata em cada uma das áreas de coleta foram capturados 98 espécimes com armadilhas luminosas tipo CDC e houve o predomínio da Pi. fischeri (45,92\%) seguido por Ps. Iloydi (29,59\%), Ny. whitmani (10,20\%) e Mi. migonei (5,10\%), principalmente nos ecótopos de Mata seguido pelo ecótopo periurbano (Tabela 1). 
Tabela 1 -Número de espécimes capturados na borda da mata com armadilha luminosa tipo CDC, por espécie e sexo, em cada área de coleta no município de Bom Jesus dos Perdões, no período de fevereiro/junho do ano de 2014

\begin{tabular}{|c|c|c|c|c|c|c|c|c|c|c|c|c|c|c|c|c|c|c|c|c|c|c|c|c|c|c|}
\hline \multirow[b]{2}{*}{ Sexo } & \multicolumn{2}{|c|}{ Área 1} & \multicolumn{2}{|c|}{ Área 2} & \multicolumn{2}{|c|}{ Área 3} & \multicolumn{2}{|c|}{ Área 4} & \multicolumn{2}{|c|}{ Área 5} & \multicolumn{2}{|c|}{ Área 6} & \multicolumn{2}{|c|}{ Área 7} & \multicolumn{2}{|c|}{ Área 8} & \multicolumn{2}{|c|}{ Área 9} & \multicolumn{2}{|c|}{ Área 10} & \multicolumn{2}{|c|}{ Área 11} & \multicolumn{2}{|c|}{ Área 12} & \multicolumn{2}{|c|}{ Total } \\
\hline & $\mathbf{M}$ & $F$ & M & $F$ & M & $F$ & M & $\mathbf{F}$ & M & $F$ & $\mathbf{M}$ & $F$ & M & $F$ & M & $F$ & $\mathbf{M}$ & $\mathbf{F}$ & $\mathbf{M}$ & $\mathbf{F}$ & $\mathbf{M}$ & $F$ & $\mathbf{M}$ & $\mathbf{F}$ & $\mathbf{M}$ & $\mathbf{F}$ \\
\hline Pi. fischeri & - & 9 & 1 & 2 & - & 3 & 4 & 1 & 1 & - & 2 & - & - & 2 & - & - & - & - & - & 22 & - & - & - & - & 6 & 39 \\
\hline Mi. migonei & - & - & 3 & - & - & - & - & - & - & - & - & - & 1 & - & - & 1 & - & - & - & - & - & - & - & - & 4 & 1 \\
\hline Ny. whitmani & - & - & 1 & - & - & - & - & - & - & - & 8 & 1 & - & - & - & - & - & - & - & - & - & - & - & - & 9 & 1 \\
\hline Ev. edwardsi & - & - & - & - & - & - & - & - & - & - & - & 1 & - & - & - & - & - & - & - & - & - & - & - & - & - & 1 \\
\hline Ps. arthuri & 2 & 1 & - & - & - & - & - & - & - & - & - & - & - & - & - & - & - & - & - & 1 & - & - & - & - & 2 & 2 \\
\hline Ps. Iloydi & 2 & - & 1 & 1 & 8 & 3 & 3 & 2 & - & 1 & - & - & 1 & 4 & - & - & - & - & - & 3 & - & - & - & - & 15 & 14 \\
\hline Ps. ayrozai & - & 1 & - & - & - & - & - & - & - & - & - & - & - & - & - & - & - & - & - & 1 & - & - & - & - & - & 2 \\
\hline Ma. alphabetica & - & - & - & - & - & - & - & - & - & - & - & - & - & - & - & 1 & - & - & - & - & - & - & - & - & - & 1 \\
\hline Pa. lanei & - & - & - & - & - & - & - & - & - & - & - & - & - & - & - & - & - & - & - & - & - & - & - & - & - & 1 \\
\hline
\end{tabular}

Fonte: (COSTA, L. E. S., 2015).

O número de espécimes capturados com a armadilha tipo Shannon foi muito superior quando comparado à armadilha luminoso tipo CDC, com predomínio da espécie Pi. fischeri (67,54\%) seguido pelas espécies Mg.migonei (10,38\%), $N y$. whitmani $(9,46 \%)$ e Ps. Iloydi (8,02\%), apenas a espécie Pa. lanei não foi capturada com esse tipo de armadilha (Tabela 2). 
Tabela 2 - Número de espécimes capturados com armadilha de Shannon, por espécie e sexo, em cada área de coleta no município de Bom Jesus dos Perdões, no período de fevereiro/junho do ano de 2014

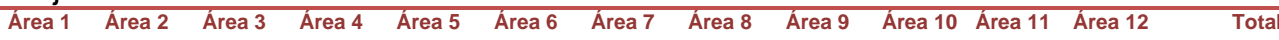

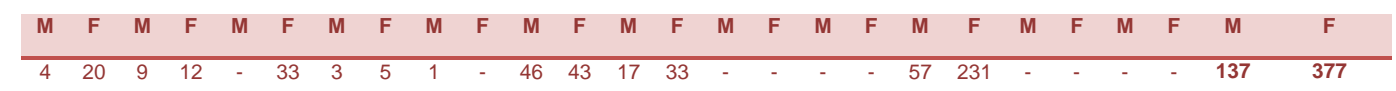

i. misionensis

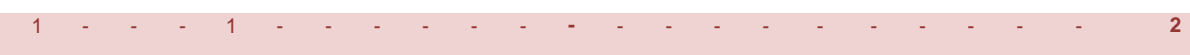

Pi. monticola

Mg. migonei

Ny. whitmani

$28 \quad 21$

$32 \quad 47$

Ev. edwardsi

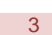

21

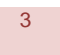

$50 \quad 22$

Ps. arthuri

Ps.llloydi

Ps. ayrozai

Ma. alphabetica

Pa.sp (série foratiniela)

Total

1

Fonte: (COSTA, L. E. S., 2015).

Nas armadilhas luminosas tipo CDC instaladas no peridomicílio de cada área de coleta foram capturados 19 espécimes, principalmente no ecótopo periurbano, predominando a espécie Pi. fischeri (47,37\%), Ny. whitmani (26,32\%), Ev. edwardsi (10,53\%) seguido pelas espécies Ps. ayrozai (5,26\%) e Pi. misionensis (5,26\%) (Tabela 3). 
Tabela 3 - Número de espécimes capturados no Peridomicílio com armadilha luminosa tipo CDC, por espécie e sexo, em cada área de coleta no município de Bom Jesus dos Perdões, no período de fevereiro/junho do ano de 2014

\begin{tabular}{|c|c|c|c|c|c|c|c|c|c|c|c|c|c|c|c|c|c|c|c|c|c|c|c|c|c|c|}
\hline & \multirow{2}{*}{\multicolumn{2}{|c|}{$\begin{array}{c}\text { Área } \\
1\end{array}$}} & \multirow{2}{*}{\multicolumn{2}{|c|}{$\begin{array}{c}\text { Área } \\
2\end{array}$}} & \multirow{2}{*}{\multicolumn{2}{|c|}{$\begin{array}{c}\text { Área } \\
3\end{array}$}} & \multirow{2}{*}{\multicolumn{2}{|c|}{$\begin{array}{c}\text { Área } \\
4\end{array}$}} & \multirow{2}{*}{\multicolumn{2}{|c|}{$\begin{array}{c}\text { Área } \\
5\end{array}$}} & \multirow{2}{*}{\multicolumn{2}{|c|}{$\begin{array}{c}\text { Área } \\
6\end{array}$}} & \multirow{2}{*}{\multicolumn{2}{|c|}{$\begin{array}{c}\text { Área } \\
7\end{array}$}} & \multirow{2}{*}{\multicolumn{2}{|c|}{$\begin{array}{c}\text { Área } \\
8\end{array}$}} & \multirow{2}{*}{\multicolumn{2}{|c|}{$\begin{array}{c}\text { Área } \\
9\end{array}$}} & \multirow{2}{*}{\multicolumn{2}{|c|}{$\begin{array}{c}\text { Área } \\
10\end{array}$}} & \multirow{2}{*}{\multicolumn{2}{|c|}{$\begin{array}{c}\text { Área } \\
11\end{array}$}} & \multirow{2}{*}{\multicolumn{2}{|c|}{$\begin{array}{c}\text { Área } \\
12\end{array}$}} & \multirow{2}{*}{\multicolumn{2}{|c|}{ Total }} \\
\hline & & & & & & & & & & & & & & & & & & & & & & & & & & \\
\hline Sexo & $M$ & $F$ & $M$ & $F$ & $M$ & $F$ & $M$ & $F$ & $M$ & $F$ & $M$ & $F$ & $M$ & $F$ & M & $F$ & $M$ & $F$ & $M$ & $F$ & $M$ & $F$ & $M$ & $F$ & $M$ & $F$ \\
\hline Pi. Fischeri & - & - & - & - & 1 & - & 2 & - & - & - & 4 & 1 & - & - & - & - & - & - & - & 1 & - & - & - & 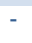 & 7 & 2 \\
\hline Pi. Misionensis & - & - & - & - & - & - & - & 1 & - & - & - & - & - & - & - & - & - & - & - & - & - & - & - & - & - & 1 \\
\hline Mi. Migonei & - & - & - & - & - & - & 1 & - & - & - & - & - & - & - & - & - & - & - & - & - & - & - & - & - & 1 & - \\
\hline Ny. Whitmani & - & - & - & - & - & - & - & - & - & - & 3 & 2 & - & - & - & - & - & - & - & - & - & - & - & - & 3 & 2 \\
\hline Ev. Edwardsi & - & - & - & - & - & - & - & - & - & - & - & 2 & - & - & - & - & - & - & - & - & - & - & - & - & - & 2 \\
\hline Ps. Ayrozai & - & - & - & - & - & - & - & - & - & - & - & - & - & - & - & - & - & - & - & 1 & - & - & - & - & - & 1 \\
\hline Total & - & - & - & - & 1 & - & 3 & 1 & - & - & 7 & 5 & - & - & - & - & - & - & - & 2 & - & - & - & - & 11 & 8 \\
\hline
\end{tabular}

Fonte: (COSTA, L. E. S., 2015).

O número de espécimes capturados com os dois tipos de armadilhas por espécie e sexo é apresentado nas Gráficos 1 e 2. A riqueza de espécies (número de espécies) variou de 1 a 8 com maior riqueza nas áreas 10 e 03, ambas com 8 espécies diferentes e capturadas com armadilha tipo Shannon (Tabela 2).

Gráfico 1 - Número de espécimes capturados, por espécie e sexo, no município de Bom Jesus dos Perdões, no período de fevereiro/junho do ano de 2014

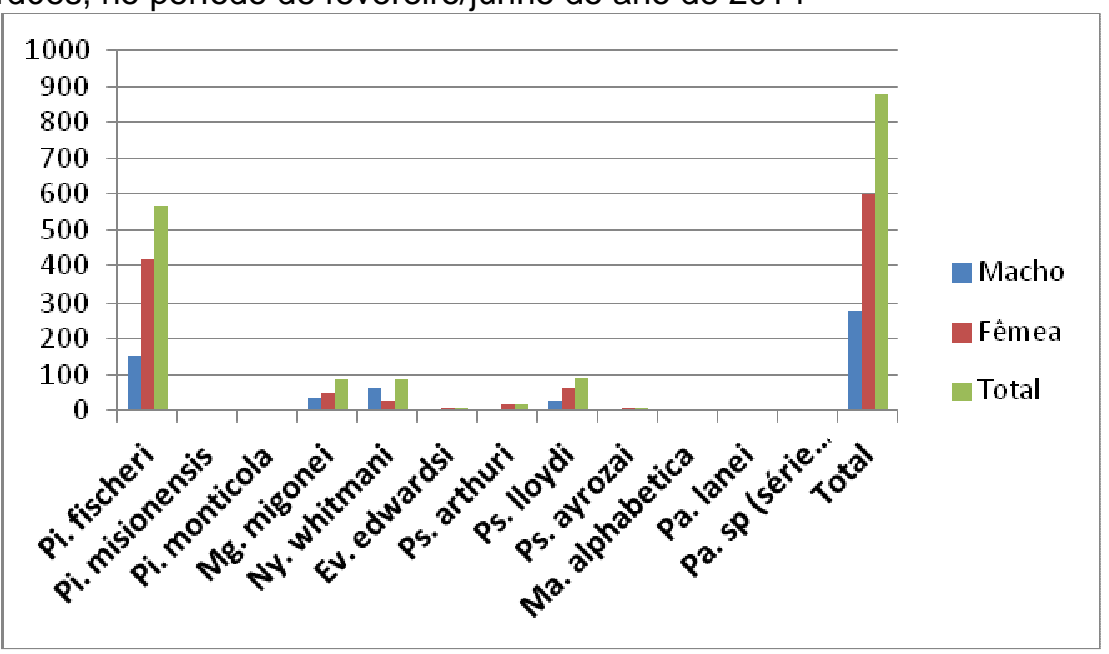

Fonte: (COSTA, L. E. S., 2015). 
Gráfico 2 - Número de espécimes capturados, por espécie e sexo, no município de Bom Jesus dos Perdões, no período de fevereiro/junho do ano de 2014, excluindo a espécie Pi. fischeri

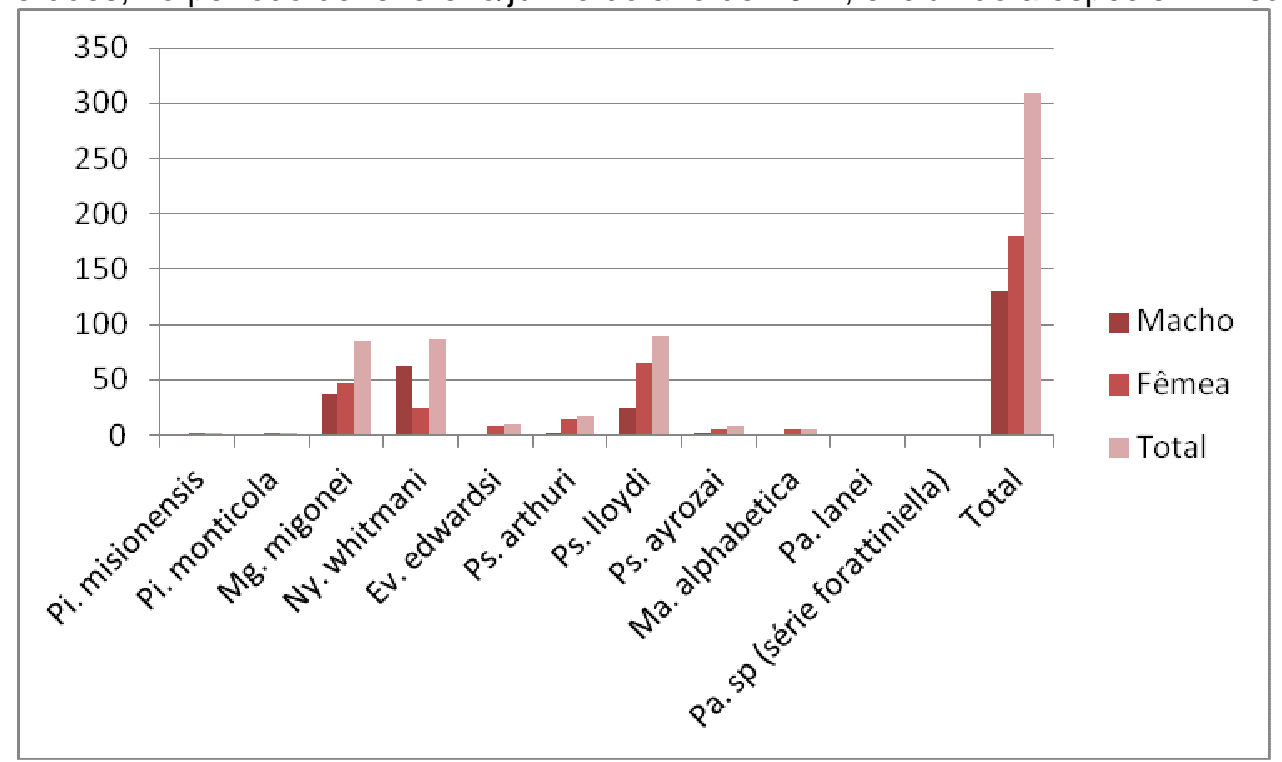

Fonte: (COSTA, L. E. S., 2015).

As espécies de flebotomíneos com seus respectivos número de espécimes por sexo capturados nas 12 áreas de coleta no município de Bom Jesus dos Perdões, no período de Fevereiro / Junho de 2014 são apresentadas nos Gráficos 1, apresentando um predomínio muito superior da espécie Pi. fischeri (64,69\%) seguido pelas espécies Ps. Iloydi (10,25\%), Ny. whitmani (9,91\%) e Mg. migonei $(9,68 \%)$. No ecótopo urbano do município de Bom Jesus dos Perdões, no período de Fevereiro / Junho de 2014 não foi capturada nenhuma espécie de flebotomíneo. Também não foi encontrada a espécie Lutzomyia longipalpis em nenhum ecótopo do município.

Foram obtidos 96 pools com as fêmeas dos flebotomineos capturados no município de Bom Jesus dos Perdões. Os pools foram feitos respeitando as espécies capturadas, ponto de coleta e tipo de armadilha. Um total de 21 pools de sete espécies diferentes e originários das áreas 1, 2, 3, 6, 7 e 10 foram positivas para parasitas do gênero Leishmania através do PCR para o gene da quitinase.

A taxa de infecção natural foi expressa como taxa mínima de infecção (TMI), calculada dividindo-se o número de grupos positivos pelo número total de espécimes testados $\times 100$, resultando em uma TMI de 3,5\%.

Todas as amostras positivas com fragmento de tamanho correspondente a espécie de Leishmania causadora da doença na forma visceral, de aproximadamente $790 \mathrm{pb}$, obtidas através do PCR para o gene quitinase foram 
confirmados como Leishmania (L.) infantum chagasi através do sequenciamento do fragmento obtido (99\% AY518251). As amostras com fragmentos com tamanho correspondente as espécies de Leishmania causadoras da doença na forma tegumentar, de aproximadamente 370 pb obtidas através do PCR para o gene quitinase, foram sequenciados, mas não há sequência correspondente nos bancos de sequencias (GenBank) e as amostras de referência de cada espécie estão em processo de sequenciamento para a comparação com as sequencias obtidas neste estudo.

Os lotes para as diferentes espécies de Leishmania foram submetidos a PCR para analisar a preferência alimentar das espécies de flebotomíneos capturados através da amplificação e sequenciamento do gene de citocromo $B$ de vertebrados. Todos os lotes foram positivos na amplificação do gene, mas somente três lotes resultaram em sequenciamento confiável.

Na área 6 um pool de Pi. fischeri foi positiva para Leishmania causadora da doença na forma tegumentar, apresentando ter se alimentado em cão (100\% JX849651) e Ny. whitmani também positiva para Leishmania causadora da doença na forma tegumentar, apresentando ter se alimentado em humano $(100 \%$ KF126161). Na área 7 um pool de Pi. fischeri foi positiva para L. (L.) infantum chagasi, apresentando ter se alimentado em humano (100\% KF126161).

Os fragmentos obtidos também foram clonados e sequenciados. Dos 21 pools positivos foram realizados os ensaios de PCR para os genes SSUrDNA e citocromo $B$, mas todas as amostras foram negativas. 


\section{DISCUSSÃO}

Bom Jesus dos Perdões apresenta grande parte de seu território dentro do Parque Estadual da Serra do Itapetinga, localizado próximo a Serra da Cantareira e a Serra do Itaberaba, apresentando uma importante área remanescente de Mata Atlântica do estado.

Este estudo observou a diversidade da fauna de flebotomíneos no município de Bom Jesus dos Perdões coletados com armadilha luminosa tipo CDC e Barraca de Shannon, no período de Fevereiro a Junho de 2014, em 12 áreas localizadas em três ecótopos: área de Mata, área Periurbana e área Urbana e constatou uma riqueza de 12 espécies de flebotomíneos.

Capturas de flebotomíneos no Parque Estadual da Cantareira realizadas pelo Centro de Controle de Zoonoses da Prefeitura Municipal de São Paulo e Divisão de Programas Especiais da Superintendência de Controle de Endemias, constataram a presença de Pi. fischeri, Mg. migonei, Ps. lloydi, Ny. intermedia, Ny. whitmani, Pa. pascalei, Ps. arthuri, Ma. alphabetica, Ps. ayrozai, Pi. monticola, Ev. edwardsi e Ex. firmatoi, totalizando 12 espécies (MOSCHIN, 2010).

Em comparação com a fauna de flebotomíneos encontrada na Serra da Cantareira, não foram encontrados nas capturas realizadas neste estudo as espécies Ny. intermedia, Pa. pascalei, Ex. firmatoi, porém, observou outras espécies como Pintomyia misionensis, Psathyromyia lanei e Psathiromyia sp (série) forattiniella.

Quando observamos a abundância relativa de cada vetor constatamos que dentre as espécies coletadas Pi. fischeri (62,48\%), Ps. Iloydi (9,90\%), Ny. whitmani (9,57\%), Mg. migonei (9,35\%) e são as espécies proporcionalmente mais abundantes.

Segundo Gomes e Galati (1977) o habitat florestal é essencial para o desenvolvimento de flebotomíneos. Porém, atualmente algumas discussões surgem para explicar a capacidades de algumas espécies de flebotomíneos sobreviverem em áreas impactadas $\mathrm{e}$ até mesmo no ambiente urbano. As mudanças comportamentais de alguns flebotomíneos podem estar ocorrendo devido às variações climáticas globais e modificações ambientais (SHAW, 2008). 
Seguindo esta lógica as Leishmanioses estariam se expandindo além do habitat florestal devido os distúrbios ambientais de diferentes naturezas, ocasionando uma maior exposição do homem aos insetos vetores (SHAW, 2007, 2008).

A detecção de flebotomíneos naturalmente infectados nas áreas endêmicas, assim como a identificação correta da espécie de Leishmania que é de primordial importância para epidemiologia das Leishmanioses (SILVA et al., 1999).

Para detecção dos parasitas do gênero Leishmania nos flebotomíneos, 0 método mais empregado sempre foi à dissecção do aparelho digestivo do díptero, seguido do exame microscópio entre lâmina e lamínula. Neste caso, a positividade das amostras deve ser confirmada com o isolamento do parasito em meio de cultura e/ou inoculação em animais de laboratório, uma vez que outros flagelados podem ser encontrados no trato digestivo destes insetos (DIAS, 2015).

Um fator limitante para está técnica é a dificuldade de processar grande número de espécimes capturados nas áreas de elevada transmissibilidade, uma vez que o procedimento é trabalhoso e exige muita experiência e perícia técnica do profissional. A investigação de infecção natural por Leishmania através do uso do método convencional de dissecção de flebotomíneos fêmeas em geral apresentam índices que se situam abaixo de 1\% para as distintas áreas endêmicas investigadas tanto no Brasil como em outros países da América do Sul (DIAS, 2015).

Com a introdução de novas estratégias para identificação de infecção natural em flebotomíneos, estes índices apresentam considerável aumento. Métodos moleculares baseados na reação em cadeia da polimerase (PCR) têm sido ultimamente utilizados em estudos para detecção de infecção natural e observa-se um aumentado da sensibilidade e especificidade da identificação de Leishmania spp., porém não é possível determinar do número, estágio e localização do parasito no vetor. Esses métodos possibilitam maior rapidez na análise de uma grande amostragem, a técnica permite trabalhar com insetos mantidos a seco, congelados ou conservados em etanol, sem interferir no desempenho da reação (DIAS, 2015).

Algumas espécies de flebotomíneos não reconhecidas como vetores de Leishmania spp, desenvolvem naturalmente (CARVALHO et al., 2008; SAVANI et al., 2009) ou experimentalmente infecção pelos parasitas (PAIVA et al., 2007; ROGERS; BATES, 2007) 
O encontro de infecção natural em flebotomíneos que são reconhecidos no conceito de vetores permissíveis mostra a necessidade de investigar outras espécies que poderiam atuar na transmissão dos agentes das Leishmanioses. Neste sentido, são de particular interesse, espécies que possam atuar na cadeia de transmissão das Leishmanioses (DIAS, 2015).

Segundo o SINAN - Sistema de Informação de Agravos de Notificação, a leishmaniose tegumentar americana (LTA) ocorreu no município de Bom Jesus dos Perdões nos anos de 2010 a 2015 nos três ecótopos do estudo, ou seja, em área Urbana, área Periurbana, e em área de Mata.

Foram 04 casos de LTA no período, sendo 03 casos autóctones e as espécies de flebotomíneos que apresentaram maior abundância foram Pi. fischeri, Ny. whitmani, Mg. migonei, Ps. lloydi e Ps. ayrozai. Foi constatada infecção natural nas espécies Pi. fischeri, Ny. whitmani, Mg. migonei, Ev. edwardsi, Ps. ayrozai e Ps. Iloydi, todas positivas para Leishmanias causadoras da doença na forma tegumentar.

A espécie Pi. fischeri foi a mais abundante da fauna flebotomínica no município, considerando todos os locais de captura deste estudo.

Em outros municípios paulistas, também, já haviam sido observadas fortes evidências de que Ny. whitmani, Mg. migonei, Pi. fischeri e Ps. ayrozai pudessem manter o ciclo silvestre da Leishmania (V) braziliensis (TOLEZANO et al., 2001b).

Outros autores também indicaram Pi. fischeri, no estado de São Paulo, município de Botucatu, como possível vetor de Leishmania (V) braziliensis na área (CUTOLO et al., 2013).

Também na Serra da Cantareira, região da Grande São Paulo, a espécie apareceu como um possível vetor, pela predominância e antropofilia (MOSCHIN et al., 2013).

E se baseando na alta abundância da espécie Pi. fischeri em área de ocorrência de LTA no município associada com os resultados positivos da infecção natural para espécies de Leishmania causadoras da doença na forma tegumentar, essa espécie poderia ser incriminada como uma da principais vetoras da LTA no município de Bom Jesus dos Perdões.

A leishmaniose visceral encontra-se em expansão no estado de São Paulo e vem acometendo populações humanas e caninas de vários centros urbanos. 
Infecção na população canina e felina tem sido identificadas na região metropolitana da Grande São Paulo sem que a espécie Lutzomyia longipalpis, tenha sido encontrada. Em Cotia e Embu a transmissão da leishmaniose visceral ocorre em ambiente de transição urbano-rural, que apresentam resíduos de matas nos quais os flebotomíneos antropofílicos, Pintomyia fischeri e Migonemyia migonei se desenvolvem (GALVIS, 2011).

Segundo Galvis (2011), Lu. longipalpis apresenta a capacidade vetorial em relação a Leishmania (L.) infantum chagasi 18,7 vezes à de Pi. fischeri e esta espécie 45 vezes à de $M g$. migonei. Também relata que, no foco de leishmaniose visceral canina da região Embu/Cotia, a espécie Pi. fischeri poderia atuar na transmissão desta doença em virtude da sua densidade elevada e infecção experimental.

O município de Bom Jesus dos Perdões não apresenta casos de Leishmaniose Visceral (humana ou canina) e a presença do vetor Lutzomyia longipalpis, mas foi constatada a infecção natural para L. (L.) infantum chagasi nas espécies Pi. fischeri, Mg. migonei e Ma. alphabetica, nas áreas 2 e 7 indicando uma possível circulação da Leishmania causadora da doença na forma visceral, em reservatórios silvestres em área Periurbanas.

Os dados deste estudo indicam que no município de Bom Jesus dos Perdões os casos de Leishmaniose Tegumentar ocorrem nas áreas de Mata e áreas Periurbanas, principalmente devido à ação antrópica que vem ocorrendo ao longo dos anos, mudando o meio ambiente. Também é importante ressaltar a presença das espécies Pi. fischeri, Ps. lloydi, Ny. whitmani e Mg. migonei nas áreas de bolsões de matas e capoeiras com a presença do homem, animais domésticos e silvestres.

Quanto a Leishmaniose Visceral, este estudo aponta que o município é vulnerável principalmente por estar localizado próximo a centros urbanos como Campinas e municípios da Grande São Paulo, onde já ocorre a transmissão da Leishmania (L.) infantum chagasi, em ambiente de transição urbano-rural. Tal constatação mostra o aumento do risco de transmissão das Leishmanioses e aponta para uma maior importância das medidas de vigilância entomológica, da fiscalização do uso e ocupação do solo. Entretanto, estudos mais detalhados objetivando o isolamento das diferentes espécies de Leishmania nos hospedeiros vertebrados é 
essencial para a confirmação dos resultados encontrados no município de Bom Jesus dos Perdões.

Neste estudo, foi possível detectar a infecção de fêmeas de flebotomíneos por Leishmania sp pela primeira vez no município de Bom Jesus dos Perdões, ficando a taxa mínima de infecção natural do município em $3,5 \%$, mostraram-se próximas às detectadas por pesquisas anteriores. 


\section{CONCLUSÕES}

- Com esse estudo observou-se uma riqueza de 12 espécies de flebotomíneos distribuídos em duas Subtribos: Subtribo Lutzomyiina com Migonemyia migonei, Pintomyia fischeri, Pintomyia monticola, Pintomyia misionensis, Evandromyia edwardsi e a Subtribo Psychodopygina com Psathyromyia lanei, Psathyromyia sp (série) forattiniella, Martinsmyia alphabetica, Psychodopygus arthuri, Psychodopygus Iloydi, Psychodopygus ayrozai e Nyssomyia whitmani.

- As espécies proporcionalmente mais abundantes foram Pi. fischeri (62,48\%), Ps. Iloydi (9,90\%), Ny. whitmani (9,57\%), Mg. migonei (9,35\%).

- Não foi capturada nenhuma espécie de flebotomíneo no ecótopo urbano do município de Bom Jesus dos Perdões, no período de Fevereiro / Junho de 2014.

- Não identificamos a presença da espécie Lutzomyia longipalpis no município.

- Os resultados sugerem a infecção natural para Leishmanias causadoras da doença nas formas tegumentar e visceral nos flebotomíneos capturados de $3,5 \%$.

- O estudo também constatou que pools das espécies Pintomyia fischeri apresentavam ter se alimentado em cães e humanos e a espécie Nyssomyia whitmani apresentou ter se alimentado em cães. Mas não podemos descartar possíveis contaminações durante alguma fase da pesquisa. 


\section{REFERÊNCIAS}

ADLER, S.; THEODOR, O. The mounth parts, alimentary tract and salivar apparatus of the females in Phlebotomus papatasi. Annals Tropical Medicine Parasitology, v.20, p.109-142, 1926.

ADLER, S.; THEODOR, O. Transmission of disease agents by phlebotomine sandflies. Annual Review of Entomology, Palo Alto, v. 2, p. 203-226, 1957.

ALEXANDER, B. Sampling methods for phlebotomine sandflies. Medical and Veterinary Entomology, Oxford, v. 14, n. 2, p. 109-122, 2000.

ANDRADE, A. R. O.; DORVA, M. E. M. C.; ANDRADE, S. M. O.; MARQUES, A.; SILVA, B. A. K.; ANDREOTTI, R. Phlebotominefauna in the Ponta Porã city: epidemiologicalimportance in border line between Brazil and Paraguay. Asian Pacific Journal of Tropical Disease, Hong Kong, v. 2, n. 5, p. 362-366, 2012.

AGUIAR, G. M.; MEDEIROS, W. M. Distribuição regional e hábitats das espécies de flebotomíneos do Brasil, In: RANGEL E. F.; LAINSON, R. (Org.). Flebotomíneos do Brasil, Rio de Janeiro: Editora FIOCRUZ, 2003. p. 207- 255.

AGUIAR, G. M.; VILELA, M. L.; LIMA, R. B. Ecology of the sandflies of Itaguai, an area of cutaneous leishmaniasis in the State of Rio de Janeiro. Food preferences (Diptera, Psychodidae, Phlebotominae). Memórias do Instituto Oswaldo Cruz, v. 82, p. 583-4, 1987.

ALVAR, J.; VÉLEZ, I. D.; BERN, C.; HERRERO, M.; DESJEUX, P.; CANO, J; JANNIN, J; DEN BOER, M. Leishmaniasis Worldwide and Global Estimates of Its Incidence. PLoS ONE, v. 7, n. 5, p. 35671, 2012.

ALVES, J. M. P. Caracterização e filogenia molecular de Acanthamoeba. $194 \mathrm{f}$. Tese (Doutorado) - Instituto de Ciências Biomédicas da Universidade de São Paulo, São Paulo, 2001.

ALVES, W. A. Leishmaniose visceral americana: situação atual no Brasil, coordenação geral de doenças transmissíveis. Brasília: Departamento de Vigilância Epidemiológica. Secretaria de Vigilância em Saúde. Ministério da Saúde, 2005.

ANTUNES, P. C. A. Notas sobre Flebotomus Sul-Americanos. I. Um novo Flebotomus, Flebotomtus iloydi, encontrado em São Paulo (Diptera, Psychodidae). Revista Biologia e Hygiene, São Paulo, v.8, p. 24-26, 1937. 
ANTUNES, P. C. A.; COUTINHO, J. 0. Notas sobre flebótomos sul-americanos. H. Descrição de Flebotomus whitmani n. sp. e de armadura bucal de algumas espécies. Boletim de Biologia, São Paulo, v. 4, p. 448-453, 1939.

ARTEMIEV, M. M. A classification of the subfamily Phlebotominae. Parassitology, v. 33, p. 69-77, 1991. Supplement, 1.

BANETH, G.; KOUTINAS, A.; SOLANO-GALLEGO, L. B.; FERRER, L. Canine leishmaniosis -new concepts and insights on an expanding zoonosis: part one. Trends in Parasitology, v. 24, n. 7, p. 324-330, 2008.

BARRETO, M. P. Novos subgêneros de Lutzomyia França, 1924 (Diptera, Psychodidae, Phlebotominae). Ver. Instituto de Medicina Tropical de São Paulo, v. 2, p. 91-100, 1962.

BARRETO, M. P. Sobre a sistemática da Subfamília Phlebotominae Rondani (Diptera,Psychodidae). Revista Brasileira de Entomologia, v. 3, p.173-190, 1955.

BRASIL. Ministério da Saúde. Manual de Vigilância e Controle da Leishmaniose Visceral. Brasília: Ministério da Saúde, 2013.

BRASIL. Ministério da Saúde. Manual de Vigilância e Controle da Leishmaniose Visceral. Brasília: Ministério da Saúde, 2014.

BRASIL. Ministério da Saúde. Secretaria em Saúde. Departamento de Vigilância Epidemiológica. Manual de vigilância da leishmaniose tegumentar americana. 2. ${ }^{a}$ ed. Brasília: Editora Ministério da Saúde, 2007.

BOM JESUS DOS PERDÕES. (Município). Prefeitura Municipal da Estância Hidromineral de Amparo. Plano municipal de desenvolvimento rural sustentável, Bom Jesus dos Perdões, 2009- 2013.

CACERES, A. G. Distribucion geografica de Lutzomyia verrucarum (Townsend, 1913) (Diptera, Psychodidae, Phlebotominae), vector de la batonellosis humana en el Peru. Revista do Instituto de Medicina Tropical de São Paulo, São Paulo, v. 35, n. 6, p. 485-490, 1993. 
COLACICCO-MAYHUGH, M. G.; MASUOKA, P. M.; GRIECO, J. P. Ecological niche model of Phlebotomus alexandri and $P$. papatasi (Diptera: Psychodidae) in the Middle East. International Journal of Health Geographics, London, v. 9, n. 2, p.19, 2010.

CAMARGO-NEVES, V.L. SÃO PAULO (Estado) Secretaria da Saúde. Superintendência de Controle de Endemias (SUCEN). Coordenadoria de Controle de Doenças (CCD). Coordenação...Manual de vigilância e controle da leishmaniose visceral americana do Estado de São Paulo, São Paulo, 2006.

CARREIRA-ALVES, J R. Espécies de Phlebotominae (Diptera: Psychodidae) da Fazenda São José, Município de Carmo, Estado do Rio de Janeiro, Brasil. 2008. 133 p. Dissertação (Mestrado em Biologia Animal) - Instituto de

Biologia,Universidade Federal Rural do Rio de Janeiro, Rio de Janeiro, 2008.

CARVALHO, E. M.; FILHO, D. C.; BACELLAR, O.; ALMEIDA, R. P.; LESSA, H.; $\mathrm{ROCHA}, \mathrm{H}$. Characterization of the immune response in subjects with self-healing cutaneous leishmaniasis. The American Journal of Tropical Medicine and Hygiene, 1995; v. 53, n. 3, 273-277, 1995.

CASANOVA, C.; COLLA-JACQUES, F. E.; HAMILTON, J. G. C.; BRAZIL, R. P.; SHAW, J. J. (2015) Distribution of Lutzomyia longipalpis Chemotype Populations in São Paulo State, Brazil. PLoS Neglected Tropical Disiases, 2015, v. 9, n. 3: e0003620. doi:10.1371/journal.pntd.0003620.

CHANCE, M. L. The biochemical and immunotaxonomy of Leishmania. In: Leishmaniasis. 1nd ed. Chang MP, Bray RS. Elsevier Science Publishing Company, Inc. USA; 1985.

COSTA, F. P. L. Medindo a diversidade. La Insignia. Independente. 2007. Disponível em: <https://pt.wikipedia.org>. Acesso em: 03 jul. 2016.

COSTA LIMA, A. Sobre os Phlebotomos americanos (Diptera: Psychodidae). Mernórias do Instituto Oswaldo Cruz, v. 26, p.15-69, 1932.

COUTINHO, S. G.; OLIVEIRA, M. P.; DA-CRUZ, A. M.; DE-LUCA, P. M.; MENDONÇA, S. C.; BERTHO, A. L.; SOONG, L.; MC-MAHON-PRATT, D. T-cell responsiveness of American cutaneous leishmaniasis patients to purified Leishmania pifanoi amastigote antigens and Leishmania braziliensis promastigote antigens: immunologic patterns associated with cure. Experimental Parasitology, v. 84, n. 2, p. p. 144-155, 1996.

CUTOLO, A. A.; GALATI, E. A. B.; VON ZUBEN, C. J. Flebotomíneos (Diptera, Psychodidae) em áreas de floresta no município de Botucatu, centro-oeste do 
Estado de São Paulo, Brasil. Journal of Venomous Animals and Toxins including Tropical Diseases, v.19, 2013.

DA-CRUZ, A. M.; CONCEIÇÃO-SILVA, F.; BERTHO, A. L.; COUTINHO, S. G. Leishmania-reactive CD4+ and CD8+ $T$ cells associated with cure of human cutaneous leishmaniasis. Infection and Immunity, v. 62, n. 6, p. 2614-2618, 1994.

DEDET, J.P.; VIGNES, R.; RANGEL, E. F. Morfologia e taxonomia: grupo CIPA. In: RANGEL, E. F.; LAINSON, R. (Org.). Flebotomíneos do Brasil. Rio de Janeiro: Editora Fiocruz. cap. 2, p. 177-184, 2003.

DESJEUX, P. Leishmaniasis: current situation and new perspectives. Comparative Immunology, Microbiology and Infectious Diseases, Oxford, v. 27, n. 5, p. 305318. 2004.

DIAS, Q. N. P. Avaliação do teste rápido Sandfly para infecção natural por Leishmania em flebotomíneos. 2015. 112 p. Dissertação (Mestrado) - Escola Nacional de Saúde Pública Sergio Arouca, Rio de Janeiro, 2015.

DUJARDIN, J. P.; BERMÚDEZ, H.; GIANELLA, A.; CARDOZO, L.; RAMOS, E.; SARAVIA, R.; QUIROZ, K.; FORGUES, G.; CARAZAS, R.; HERVAS, D.; CHAVEZ, T.; MACHANE, M.; MARTÍNEZ, E.; TORREZ, M. Uso de marcadores geneticos en la vigilancia entomologica de la enfermedad de Chagas. In: CASSAB, J. A.; NOIREAU, F.; GUILLEN, G. (Ed.). La Enfermedad de Chagas em Bolivia - Conocimientos científicos al inicio del Programa de Control (1998-2002). Brasília: Ministerio de Salud y Prevision social, OMS/OPS, IRD and IBBA, 1999.; p.157-169, 1999.

FAIRCHILD, G. B. A note on Hertigia hertigi Fchld. and description of the female. Proceedings of the Entomological Society of Washington, 1953.; v. 55, p.101102. 1953.

FAIRCHILD. G. B. The relationship and classification of the Phlebotominae (Diptera, Psychodidae). Annals of the Entomological Society of America, 1955.; v. 48, p.182-196, 1955.

FOCACCIA, R. V.; VERONESI, R. Tratado de infectologia. 4. ed. São Paulo: [s.n.], 2010.

FONSECA, F. Flebotomus das cercanias de cidade de S. Paulo, com a descrição de Febotomms arthurin. sp. e F. alphabeticus n. op. (Dipt., Psychodidae). Revista de Entomologia, 1936.; v. 6, p. 323-327, 1936. 
FORATTINI, O. P. Sobre a classificação da subfamilia Phlebotominae nas Americas (Diptera, Psychodidae). Papeis Avulsos, São Paulo. 1971a.; v. 24, p. 93-111, 1971.

FORATTINI, O. P. Entomologia Medica. São Paulo: ED. Edgar Blucher-EDUSP, 1973.; p. 640, 1973.

FRANÇA, C. Observation sur le genre Phlebotomus. Botéria, (Série Zoológica), 1919.; v. 17, p. 109-160, 1919.

FRANÇA, C. Notes parasitologiques. Jornal Sciêntia, Mathemáticas, Physica e Naturales, Lisboa, v. 3, p. 17, 1924. Separata 12.

FRANÇA, C.; PARROT, L. Introducion à l'étude systématique des Diptères du genre Phlebotomus. Bulletin de la Société de pathologie exotique, 1920.; v. 13, p. 695708, 1920.

FRANÇA, C.; PARROT, L. Essai the classification des Phlébotomes. Arch Inst Pasteur L'Afrique Nord. 1921.; v.1, p. 279-284, 1921.

FRAIHA, H.; SHAW, J. J.; LAINSON, R. Phlebotominae Brasileiros. II. Psychodopygus welcomei, nova espécie antropofila de flebotomo do grupo squamiventris, do sol do Estado de Pará, Brasil (Diptera, Psychodidae). Memórias do Instituto Oswaldo Cruz. 1971.; v. 69, p. 489-500, 1971.

GALATI, E. A. B. Phylogenetic systematics of Phlebotominae (Diptera, Psychodidae) withemphasis on American groups. Boletim da Diretoria Malariol de Saneamento Ambiental. 1995.; v. 35, p. 133-142, 1995.

GALATI, E. A. B.; NUNES, V. L. B.; DORVAL, M. E. C.; CRISTALDO, G.; ROCHA, H. C.; GONÇALVES-ANDRADE, R. M.; NAUFEL, G. Attractivesnes of Black Shannon Trap for Phlebotomines. Memórias do Instituto Oswaldo Cruz, 2001.; v. 96, n. 5, p. 641-647, 2001.

GALATI, E. A. B. Morfologia e taxonomia: classificação de Phlebotominae. In: RANGEL, E. F.; LAINSON, R. (Org.). Flebotomíneos do Brasil. Rio de Janeiro: Editora Fiocruz, 2003a. p. 23-51. 
GALATI, E. A. B. Morfologia e taxonomia: classificação de Phlebotominae. In: RANGEL, E. F.; LAINSON, R. (Org.). Flebotomíneos do Brasil. Rio de Janeiro: Editora Fiocruz, 2003b. p. 53-175.

GALATI, E. A. B. Distribuição geográfica dos Phlebotominae (Diptera, Psychodidade) das Américas. São Paulo: FSP, 2011. [(Apostila de Bioecologia e Identificação de Phlebotominae - Departamento de Epidemiologia, Faculdade de Saúde Pública da USP)].

GALVIS OVALLOS, F. Estudo da capacidade vetorial da Migonemyia migonei (França) e Pintomyia fischeri (Pinto) (Diptera:Psichodidae) para Leishmania (Leishmania) infantum chagasi Cunha \& Chagas. 2011. 107 p. Dissertação (Mestrado) - Faculdade de Saúde Pública, Universidade de São Paulo, São Paulo, 2011.

GOMES, A. C.; GALATI, E. A. B. Flebotomíneos de Londrina, Paraná (Brasil) e observações ecológicas sobre algumas espécies. Revista de Saúde Pública, v. 11, p. 284-287, 1977.

GOTO, H.; LAULETTA, J. A. L. Cutaneous and Mucocutaneous Leishmaniasis Infect Dis Clin North Am. 2012.; v. 26, n. 2, p. 293-307, 2012.

HAMILTON, P. B.; ADAMS, E. R.; NJIOKOU, F.; GIBSON, W. C.; CUNY, G.; HERDER, S. Phylogenetic analysis reveals the presence of the Trypanosoma cruzi clade in African terrestrial mammals. Infection, Genetics and Evolution, 2009.; v. 9, n. 1, p. 81-6, 2009.

HAMILTON, P. B.; GIBSON, W. C.; STEVENS, J. R. Patterns of co-evolution between trypanosomes and their hosts deduced from ribosomal RNA and proteincoding gene phylogenies. Molecular Phylogenetics and Evolution, 2007.; v. 44, n. 1, p. 15-25, 2007.

HAMILTON, P. B.; STEVENS, J. R.; GAUNT, M. W.; GIDLEY, J.; GIBSON, W. C. Trypanosomes are monophyletic: evidence from genes for glyceraldehyde phosphate dehydrogenase and small subunit ribosomal RNA. International Journal for Parasitology, 2004.; v. 34, n. 1, p. 1393-404, 2004.

HERTIG, M. Sand flies of the genus Phlebotomus. A review of their habits, disease relationships and control. In: INTERNACIONAL CONGRESS TROPICAL MEDICINE MALARIA, 4., 1948, [S.I.]. 1948b. v. 2. p. 1609-1618.

JOSHI, M. B.; ROGERS, M. E.; SHAKARIAN, A. M.; YAMAGE, M.; AL-HARTHI, S. A.; BATES, P. A.; DWYER, D. M. Molecular characterization, expression, and in vivo 
analysis of LmexCht1: the chitinase of the human pathogen, Leishmania mexicana. Journal of Biological Chemistry, 2005.; v. 280, p. 3847-3861, 2005.

KILLICK-KENDRICK, R.; WILKES, T.J.; BAILLY, M.; BAILLY, I.; RIGHTON, L. A. Preliminary field observations on the flight speed of a phlebotomine sandfly. Transactions of the Royal Society of Tropical Medicine and Hygiene, 1986.; v. 80 , n. 1, p. 138-42, 1986.

KUHLS, K.; ALAM, M. Z.; CUPOLILLO, E.; FERREIRA, G. E. M.; MAURICIO, I. L.; ODDONE, R.; FELICIANGELI, M. D.; WIRTH, T.; MILES, M. A.; SCHÖNIAN, G. Comparative microsatellite typing of New World Leishmania infantum reveals low heterogeneity among populations and its recent Old World origin. Plos Neglected Tropical Diseases, 2011.; v. 5, n. 6, p.1155, 2011.

LAINSON, R. The role of animals in the epidemiology of South American Leishmaniasis. In Lumsden W. H. R. \& Evans D. A. [Eeds.]. The biology of the kinetoplastida. London: Academic Press, 1979. Vol. 2. p. 1-116, 1979.

LAINSON, R.; SHAW, J.J.; RYAN, L.; RIBEIRO, R.S.M.; SILVEIRA, F.T. Leishmanissis in Brazil. XXI. Visceral leishmaniasis in the Amazon Region and further observations on the role of Luszomyia longipalpis (Lutz \& Neiva, 1912) as the vector. Transactions of the Royal Society of Tropical Medicine and Hygiene, 1985.; v.79, p. 223-226, 1985.

LARROUSSE, F. Nouvelle espèce américine du genre Phlebotomus brumpti sp. nov. Bulletin de la Société de pathologie exotique, 1920.; v. 13, p. 659-662, 1920.

LENG, Y. J. Survey of phelebotomine ssndflies in limestone caves of Sichuan and Guizhou Provinces, south-west China, description and discussion of a primitive genus Chinius. Annals of Tropical Medicine and Public Health, 1987.; v. 81, p. 311-317, 1987.

LEWIS, D. J.; YOUNG, D. G.; FAIRCHILD, G. B.; MINTER, D. M. Proposals for a stable classification of the phlebotomine sandflies (Diptera: Psychodidae).

Systematic Entomology, 1977.; v. 2, p. 319-332, 1977.

MAIA DA SILVA, F.; RODRIGUES, A. C.; CAMPANER, M.; TAKATA, C. S. A.; BRIGIDO, M. C.; JUNQUEIRA, A. C. V.; COURA, J. R.; TAKEFA, G. F.; SHAW, J. J.; TEIXEIRA, M. M. G. Randomly amplified polymorphic DNA analysis of Trypanosoma rangeli and allied species from human, monkeys and other sylvatic mammals of the Brazilian Amazon disclosed a new group and a species-specific marker.

Parasitology, 2004a;128:283-94. 
MAIA DA SILVA, F.; NOYES, H.; CAMPANER, M.; JUNQUEIRA, A. C.; COURA, J. R.; ANEZ, N. Phylogeny, taxonomy and grouping of Trypanosoma rangeli isolates from man, triatomines and sylvatic mammals from widespread geographical origin based on SSU and ITS ribosomal sequences. Parasitology, 2004b.; v. 129, n. 5, p. 549-61, 2004.

MAIA DA SILVA, F.; JUNQUEIRA, A. C.; CAMPANER, M.; RODRIGUES, A. C.; CRISANTE, G.; RAMIREZ, L. E.; CABALLERO, Z. C.; MONTEIRO, F. A.; COURA, J. R.; AÑEZ, N.; TEIXEIRA, M. M. G. Comparative phylogeography of Trypanosoma rangeli and Rhodnius (Hemiptera: Reduviidae) supports a long coexistence of parasite lineages and their sympatric vectors. Molecular Ecology, 2007.; v.16, n. 33, p. 61-73, 2007.

MANGABEIRA, O. 4.a Contribuicão ao estudo dos Flebotomus. Psychodopygus n. subg. (Diptera:Psychodidae). Memórias do Instituto Oswaldo Cruz, 1941c.; v. 36, p. 237-250, 1941.

MANGABEIRA, O. 5.a Contribuigio ao estudo dos Fiebotomus. Viannamyia n. subg. (Diptera: Psychodidae). Memórias do Instituto Oswaldo Cruz, 1941d.; v. 36, p. 251-262, 1941.

MARCILI, A.; VALENTE, V. C.; VALENTE, S. A.; JUNQUEIRA, A. C.; DA SILVA, F. M.; PINTO, A. Y.; NAIFF, R. D.; CAMPANER, M.; COURA, J. R.; CAMARGO, E. P.; MILES, M. A.; TEIXEIRA, M. M. Trypanosoma cruzi in Brazilian Amazonia: Lineages $\mathrm{TCl}$ and TClla in wild primates, Rhodnius spp. and in humans with Chagas disease associated with oral transmission. International Journal for Parasitology, 2009a.; v. 39, n. 5, p. 615-23, 2009.

MARCILI, A.; LIMA, L.; CAVAZZANA, M.; JUNQUEIRA, A. C.; VELUDO, H. H.; MAIA DA SILVA, F.; CAMPANER, M.; PAIVA, F.; NUNES, V. L.; TEIXEIRA, M. M. A new genotype of Trypanosoma cruzi associated with bats evidenced by phylogenetic analyses using SSU rDNA, cytochrome $b$ and Histone $\mathrm{H} 2 \mathrm{~B}$ genes and genotyping based on ITS1 rDNA. Parasitology, 2009b.; v. 136, n. 6, p. 641-55, 2009.

MARCILI, A.; LIMA, L.; VALENTE, V. C.; VALENTE, S. A.; BATISTA, J. S.; JUNQUEIRA, A. C.; SOUZA, A. I.; DA ROSA, J. A.; CAMPANER, M.; LEWIS, M. D.; LLEWELLYN, M. S.; MILES, M. A.; TEIXEIRA, M. M. Comparative phylogeography of Trypanosoma cruzi TCllc: new hosts, association with terrestrial ecotopes, and spatial clustering. Infection, Genetics and Evolution, 2009c.; v. 9, n. 6, p. 1265-74, 2009. 
MARCILI, A.; SPERANÇA, M. A.; DA COSTA, A. P. Philogenetic relationships of Leishmania species based on trypanosomatid barcode(SSU rDNA) and g GAPDH genes: Taxonomic revision of Leishmania (L.) infantum chagasi in South America. Infection, Genetcs and Evolution, v. 25, p. 44-51, 2014.

MARCONDES, C. B. A proposal of generic and subgeneric abbreviations of phlebotomines sandflies (Diptera: Psychodidae: Phlebotominae) of the world. Entomological News, 2007.; v. 118, p. 351-356, 2007.

MARTINS, A. V.; WILLIAMS, P.; FALCÃO, A. L. Americans Sand Flies (Dptera: Psychodidae, Plhebotominae). Rio de Janeiro: Academia Brasileira de Ciências. 1978. $195 \mathrm{p}$.

MAURICIO, I. L.; HOWARD, M. K.; STOTHARD, J. R.; MILES, M. A. Genomic diversity in the Leishmania donovani complex. Parasitology, 1999 Sep.; v. 119, n. 3, p. 237-46, 1999.

MOSCHIN, J. C. Aspéctos ecológicos da fauna flebotomínica (Diptera, Psychodidae) da Parque Estadual da Cantareira (PEC) e Parque Estadual Alberto Löfgren (PEAL) região metropolitana de São Paulo, Estado de São Paulo, Brasil. 2010.111 p. Dissertação (Mestrado) - Faculdade de Saúde Pública, Universidade de São Paulo, São Paulo: 2010.

NATAL, D.; MARUCCI, D.; REIS, I. M.; GALATI, E. A. B. Modificação da armadilha CDC com testes para coletas de flebotomíneos (Diptera) Revista Brasileira de Entomologia, 1991.; v. 35, n. 4, p. 697-700, 1991.

NEWSTEAD, R. The papataci flies (Phlebothmus) of the Maltese Islands. Bulletin of entomological research, 1911.; v. 2, p. 27-78, 1911.

NEVES, D. P.; MELO, A. L.; LINARDI, P. M.; VITOR, R. W. A. Leishmaniose tegumentar americana: estudo clínico, epidemiológico e laboratorial realizado no Hospital Universitário de Campo Grande, Mato Grosso do Sul, Brasil Parasitologia humana. 11. ed. São Paulo: Editora Atheneu, 2005. p. 47-64.

NICHOLAS, K. B.; NICHOLAS J. H. B.; DEERFIELD, D. W. II. GeneDoc: analysis and visualization of genetic variation. EMBNEW News, 1997.; v. 4, p. 14, 1997.

PAIVA, B. R.; SECUNDINO, N. F. C.; PIMENTA, P. F. P.; GALATI, E. A. B.; ANDRADE J. H. F.; MALAFRONTE, R. S. Padronização de condições para detecção de DNA de Leishmania spp. em flebotomíneos (Diptera, Psychodidae) pela reação em cadeia da polimerase. Cad Saúde Pública 2007; 23:87-94. 
PELLIN, A. (Coord.). Criação de sistemas de áreas protegidas do contínuo da cantareira: serras do itaberaba e itapetinga. São Paulo: Instituto Florestal, 2010.

PENNA, H. A. Leishmaniose visceral no Brasil. Revista Brasileira Médica, 1934.; v. 48, p. 949-50, 1934.

PIMENTA, P. F. P.; SECUNDINO, N. F. C.; BLANCO, E. E. N. Interação leishmaniahospedeiro invertebrado. In: RANGEL, E. F.; LAINSON, R. (Org.). Flebotomíneos do Brasil. Rio de Janeiro: Editora Fiocruz. 2003. Cap. 5, p. 275-290.

PIRMEZ, C.; YAMAMURA, M.; UYEMURA, K.; PAES-OLIVEIRA, M.; CONCEICAOSILVA, F.; MODLIN, R.L. Cytokine patterns in the pathogenesis of human leishmaniasis. J Clin Invest., 1993; 91: 1390-1395.

POLI, A.; ABRAMO, F.; BARSOTTI, P.; LEVA, S.; GRAMICCIA, M.; LUDOVISI, A.; MANCIANTI, F. Feline leishmaniosis due to Leishmania. Veterinary Parasitology, 2002.; v. 106, p. 181-191, 2002.

RANGEL, E. F.; LAINSON, R. Flebotomíneos dos Brasil. Rio de Janeiro. Ed. Fiocruz, 2003.

RANQUE, P. Études morphologique et biologique de quelques trypanosomatides récoltés au Sénegál. 1973. Tese (Doutorado) - Universidade Aix-Marseille, França, 1973.

READY, P. D. Biology of Phebotomine Sand Flies as Vectors of Desease Agents. Annual Review of Entomology, v. 58, p. 227-250, 2013.

READY, P. D.; FRAIHA, H.; LAINSON, R.; SHAW, J. J. Psychodopygus as a genus: reasons for a flexible classification of the phlebotomnne sandflies (Diptera: Psychodidae). Journal of Medical Entomology, 1980.; v. 17, p. 75-88, 1980.

REYES-URIBE, P.; PEREIRA-DOS-SANTOS, T.; DE JESUS, J. B.; RODRIGUES, C. M.; AREVALO, J.; CUPOLILLO, A. E.; CUERVO, P. Comparative zymographic analysis of metallopeptidase of Leishmania (Viannia) peruviana and Leishmania (Viannia) braziliensis isolates from Peru. Parasitology International, Amsterdam, v. 61, n. 4, p. 513-519. 2012. 
RODRIGUES, A. C.; PAIVA, F.; CAMPANER, M.; STEVENS, J. R.; NOYES, H. A.; TEIXEIRA, M. M. Phylogeny of Trypanosoma T.diverging on SSU and ITS ribosomal sequences. Parasitology, v. 132, pt. 2, p.215-24, 2006.

ROGERS, M. E.; HAJMOVÁ, M.; JOSHI, M. B.; SADLOVA, J.; DWYER, D. M.; VOLF, P.; BATES, P. A. Leishmania chitinase facilitates colonization of sand fly vectors and enhances transmission to mice. Cellular Microbiology, 2008 Jun; 10(6): 1363-1372. doi: 10.1111/j.1462-5822.2008.01132.xPMCID: PMC2408650

RONQUIST, F.; HUELSENBECK, J. P. Bayesian phylogenetic inference under mixed models. Bioinformatics, v. 19, p. 1572-1574, 2003.

ROSS, R. (1) Note on the bodies recently described by Leishmsn and Donovan and (2) fwrther notes on Leishman's bodies. British Journal of Medicine and Medical Research, v. 2, p. 1401, 1903.

RYAN, L. Flebotomos do Estado Pará, Brasil (Diptera: Psychodidae: Phlebotominae), Belém, Pará: Institute Evandro Chagas, 1986,154 p. (Tech. Doc, No. 1).

SAVANI, E. S. M.; NUNES, V. L. B.; GALATI, E. A. B.; CASTILHO, T. M.; ZAMPIERI, R. A.; FLOETER-WINTER, L. M. The finding of Lutzomyia almerioi and Lutzomyia longipalpis naturally infected byLeishmania spp. In a cutaneous and canine visceral leishmaniases focus in Serra da Bodoquena, Brazil. Veterinary Parasitology, 2009.; v. 160, p. 18-24, 2009.

SCHLEIN, Y.; JACOBSON, R. L.; MESSER, G. Leishmania infections damage the feeding mechanism of the sandfly vector and implement parasite transmission by bite. Proceedings of the National Academy of Sciences, 1992.; v. 89, n. 994, p.48, 1992.

SCHLEIN, Y.; JACOBSON, R. L.; SHLOMAI, J. Chitinase secreted by Leishmania functions in the sandfly vector. Proceedings of the Royal Society of London B., 1991.; v. 245, p. 121-126, 1991.

SHAW, J. J.; ROSA, A. T.; SOUZA, A.; CRUZ, A. C. Os flebotomíneos brasileiros como hospedeiros e vetores de determinadas espécies. In: RANGEL, E. F.; LAIRSON, R. (Ed.) Flebotomíneos do Brasil. Rio de Janeiro: Fundação Oswaldo Cruz, 2003. p. 337-351.

SHAW, J. J. The Leishmaniases - survivel and expansion in a changing world. A mini- review. Memórias do Instituto Oswaldo Cruz. v. 12, p. 541-547, 2007. 
SHAW, J. J. How climatic and environmental variations affect the eco-epidemiology of the Leishmaniases and their control. In: WORKSHOP DE GENÉTICA E BIOLOGIA MOLECULAR DE INSETOS VETORES DE DOENÇAS TROPICAIS ENTOMOL, 3, 2008, Pernambuco. 2008. p. 13-17.

SILVA, O. S.; GRUNEWALD, J. Contribution to the sand fly fauna (Diptera: Phlebotominae) of Rio Grande do Sul, Brazil and Leishmania (Viannia) infections. Memórias do Instituto Oswaldo Cruz. 1999.; v. Sep-Oct; 94, n. 5, p. 579-582, 1999.

SILVA, J. I. G. Diversidade, isolamento e filogenia de parasitas do gênero trypanosoma em vertebrados silvestres da ilha pluvial e estação ecológica de Pirapitinga, Minas Gerais. São Paulo: falta editora publicadora, 2012.

SHIMABUKURO, P. H. F.; GALATI, E. A. B. Checklist dos Phlebotominae (Diptera, Psychodidae) do estado de São Paulo, Brasil, com comentários sobre sua distribuição geográfica. Biota Neotroprica, São Paulo, v. 11, n. 1, p. , 2011.

SUZUKI, R. B.; CABRAL, A. D.; TONHOSOLO, R.; MARCILI, A.; SANCHES, C. O. C. C. A Highly Sensitive and Specific Conventional Molecular Diagnosis for Leishmania infantum chagasi Based on a Single Copy Gene. Journal of Molecular Biomarkers \& Diagnosis 2015; 7: 269. doi:10.4172/2155-9929.1000269

SWOFFORD, J. R. PAUP: Phylogenetic analysis using parsimony, Version 4b6. Suderland: Sinauer Associates. 1998.

THEODOR, O. Classification of the Old World species of the subfamily Phlebotominae (Diptera, Psychodidae). Bulletin of entomological research 1948;39:85-115.

THEODOR, O. On the classification of American Phlebotominae. Journal of Medical Entomology 1965;2:171-197.

THOMPSON, J. D.; GIBSON, T. J.; PLEWNIAK, F.; JEANMOUGIN, F.; HIGGINS, D. G. The clustalX windons interface: flexible strategies for multiple sequence alignment aided by quality analysis tools. Nucleic Acids Research 25 4876-4882. 1997. 
TOLEZANO, J. E.; TANIGUCHI, H. H.; ELIAS, C. R.; LAROSA, R. Epidemiologia da Leishmaniose tegumentar americana (LTA) no estado de São Paulo. III. Influência da ação antrópica na sucessão vetorial da LTA. Revista Instituto Adolfo Lutz. 2001.; v. 60, n. 1, p. 47-51, 2001.

YOUNG, D. G.; DUNCAN, M. A. Guide to the identification and geographic distribution of lutzomyia sand flies in Mexico, the West Indies, Central and South America (Diptera: Psychodidae). Gainesville: Associated Publishers, 1994. 887 p.. (Memoirs of the American Entomological Institute, n. 54).

VON ZUBEN, A. P. B. Leishmaniose visceral em Campinas: descrição do primeiro foco, impacto de medidas, dificuldades e controvérsias das ações de prevenção e controle, 2014. 244 p. Tese (Doutorado) - Faculdade de Ciências Médicas, Universidade Estadual de Campinas, Campinas, 2014. 